\title{
Shamanic Trance Journey with Animal Spirits: Ancient "Scientific" Strategy Dealing with Inverted Otherworld
}

\author{
Helmut Tributsch \\ Bio-Mimetics in Energy Systems Program, Carinthia University for Applied Sciences, Villach, Austria \\ Email: helmut.tributsch@alice.it
}

How to cite this paper: Tributsch, H. (2018). Shamanic Trance Journey with Animal Spirits: Ancient "Scientific" Strategy Dealing with Inverted Otherworld. Advances in Anthropology, 8, 91-126.

https://doi.org/10.4236/aa.2018.83006

Received: June 9, 2018

Accepted: August 6, 2018

Published: August 9, 2018

Copyright (C) 2018 by author and Scientific Research Publishing Inc. This work is licensed under the Creative Commons Attribution International License (CC BY 4.0).

http://creativecommons.org/licenses/by/4.0/

\begin{abstract}
Since palaeolithic times, shamans involved animal depictions in cave ceremonies and adopted animals as helping spirits during their trance journeys. This study aims at explaining the rituals with new evidence: the shamans were acting rationally to deal with an inverted otherworld, still rooted in many traditional beliefs, and seen as an impressive natural phenomenon in superior mirages. After experimenting with unhealthy upside down positions, shamans have adopted more convenient ways to "invert" their consciousness by generating oxygen deficiency and trance for entering the inverted world. San rock art from Brandberg, Namibia, is used as a model to learn more about the logic behind shamanistic trance travel, for example aimed at attracting rain. When travelling to an inverted otherworld San shamans used, besides trance-inverting their consciousness, symbols of inversion (inverted sex, inverted body posture and body painting) and were hiding their faces. Negative hand stencils, dotted (mirage) animals and hidden faces were correspondingly used in palaeolithic caves during trance ceremonies. The animals painted on cave walls were aimed at meeting their counterparts in the other world, a condition for the termination of earthly life, to enable their successful hunting. Animals seen to behave "supernaturally" in mirages and mirage phenomena themselves became helping spirits for the voyage. The mirage of earthly objects into the sky itself served as role model for shamanic travel. Voluptuous Venus figures were carved for the inverted world. They show an inversion of reality. The conclusion is that early spiritual and religious concepts developed rationally, like other strategies for survival, in attempts to deal with an occasionally but worldwide seen natural phenomenon which suggested an inverted otherworld.
\end{abstract}

\section{Keywords}

Shamans, Trance Journey, Inverted World, Anthropology of Religion, 
Cave Art

\section{Introduction}

\subsection{Aim of Present Study}

Shamanism is a ritual, in which a spiritually respected individual, by over-exerting body and mind, attempts to reach an altered state of consciousness with the aim to interact with a spirit world for the benefit of his community. Shamanic rituals were and still are spread all over the world and date back as long as human social activities can be traced. They seem to predate religions (VanPool, 2009; Peters, 1989) and may help understanding evolution of religions. In these rituals, shamans assume contact with the other world, and even attempt to reach it, for the benefit of human social groups. The working hypothesis of the present study is simple: life in ancient time was too harsh for people to invent non-logic, imagined activities for survival. They relied on what they perceived with their senses: the only natural phenomenon, which visually suggests another world in the sky, is superior optical mirages. To early humans, such apparitions, occasionally seen as upside down landscapes and sceneries, must have represented a reality with the consequence that they have tried to deal with it skillfully and rationally. The expectation here is that acts and symbols of inversion, including the shamanic trance state, should be characteristic patterns of shamanic performance. Did early humans try to act scientifically, using logic criteria for actions?

In his work "A Scientific Theory of Culture", Bronislaw Malinovski argues that science is as old as culture itself (Malinovski, 1944). He supports this by explaining, how even simple skills, like fire making, require a series of procedures, like a scientific theory, experience with natural materials and a set of verified practical procedures to gain reproducibility of a natural phenomenon. The here presented investigation aims at a naturalistic, scientific interpretation of the origins of shamanistic journeys to the imagined spiritual other world with depicted animals and animal helping spirits. An aim is to understand the origin and purpose of ritual art known from cave paintings and dating back 40,000 years. Understanding these ancient spiritual practices means tracing down origins of religion. Examples from San (!Kung) shamanism and rock art at Brandberg, Namibia, are used as supporting evidence, because they still reflect the mentality of an early stage of a hunter-gatherer society. The rock art sites were studied by the author in place, because it was assumed that they can better be understood in context with the environment, the animals, and the changing atmospheric conditions. The rich rock art of this remarkable mountain, of Brandberg in the Namib desert, has been documented and discussed in greater detail in elaborate books (Pager, 1998; Lensen-Erz \& Erz, 2000).

Shamanism is, because of its relevance for human spiritual evolution, a very intensively studied phenomenon (e.g. Hamayon, 1990; Harner, 1982). To Eliade 
(1964) a primary attribute of shamanism is communication with the spiritual other world. Rock art with illustrations of shamanic activity promised access to the world of thoughts behind the relevant ceremonies (Lewis-Williams, 1981; Lewis-Williams \& Dowson, 1989). Detailed studies of rock art in Africa are found in Le Quellec, 2004 and Campbell, 2001.

The problem addressed in this contribution is the question, how shamans reached a reliable concept of the spiritual world, they had to deal with. It should also be found out what role the trance condition played and the role of animals, which were depicted on rock faces, some of which were selected as helping spirits for their spiritually dangerous journey. The study does not aim at an evaluation of trance experience, with its visions, itself, because this has been amply discussed in the literature, both with respect to practice and with respect to brain function (Lewis-Williams \& Dowson, 1989; Flor-Henry et al., 2017; Wright, 1989; Winkelman, 2010). It rather tries to find a rational explanation for the origin and adoption of these enigmatic trance ceremonies and their symbolic attributes, aimed at contacting the other world, by primitive or early humans.

In a past paper (Tributsch, 2000) (see also comments on it in (Le Quellec, 2005) the author has challenged the interpretation that San rock art in rain-related ceremonies is essentially depicting trance experiences of shamans (Lewis-Williams \& Dowson, 1989). There it is assumed that the human brain, destabilized by sensory deprivation during trance, reacts by creating "form-constant, trans-rational images" within the visual cortex. These are interpreted by the shamans as journey to the spirit world and depicted in rock paintings (see also Chippindale et al., 2000; Jolly, 2002). As a consequence, altered mental states are now studied as an empirical phenomenon with scientific techniques (Flor-Henry et al., 2017) and the concepts proposed by Lewis-Williams (1981) and (Lewis-Williams \& Dowson, 1989) for explaining rock and cave art receive much support.

For the author of the present paper trance experience and resulting hypothetic trance images as strategy for rainmaking and as origin for rock paintings appear to be too ineffective in practice. Such trance experience, created by a brain function subject to oxygen deprivation, cannot, for example, lead to a prediction of rain. For a shaman to become credible he must have, at least occasionally, practical success. And shamans were successful, since their trance ceremonies survived ten thousands of years. The question arises, whether primitive societies, striving for survival, actually assumed a-priori non-logic (trance) strategies in dealing with their survival problems. Or were they, as the author believes, lured into trance experience by some rational insights and arguments, which convinced them that trance was the right way to proceed? This question, whether trance originally was the consequence of a wrong hypothesis, is a very fundamental topic to be clarified for understanding our early ancestors and the origins of religion.

It was suggested by the author that San shamans were behaving rationally by 
interpreting and responding to a natural atmospheric phenomenon, a superior mirage event arising on the horizon during the still before a rainstorm (Tributsch, 2000). The giant rain giraffe, often depicted in rock paintings (see below), was recognized in the form of localized pillar like deformations of the horizon, caused by air density gradients above cool ground (Figure 1) (a photograph of this type of mirage phenomenon from San environment in Namibia is seen in Figure 199 of (Tributsch, 1996). In the course of a mirage development these mirage pillars may then split from the horizon to form a narrow ribbon, a reflection of the landscape near and parallel to the horizon. This was interpreted to be the giant mythic rain snake (compare a typical superior mirage, shown in Figure 1).

San shamans, these excellent nature observers, interpreted gradually changing patterns of developing mirages as huge moving mythic animals. What they depicted were not visions of trance experience. The ribbon above the horizon, the rain snake, broadened to occasionally clearly show part of the landscape on the horizon inverted in the sky (Figure 1). The shaman, when recognizing these atmospheric patterns, knew that rain would approach. But he did not know where the rain would fall. Therefore he assumed the difficult task to travel to the inverted realms of the "rain snake" to attract rain to the desired location. As occasionally clearly seen for the observers, the world of the rain snake in the sky was inverted, upside down (sometimes San depicted also a giant rain bull, indicating a differently formed superior mirage pattern or narrated of a double "rain snake", which can also be seen during atmospheric inversion conditions, when three images of the horizon are seen).

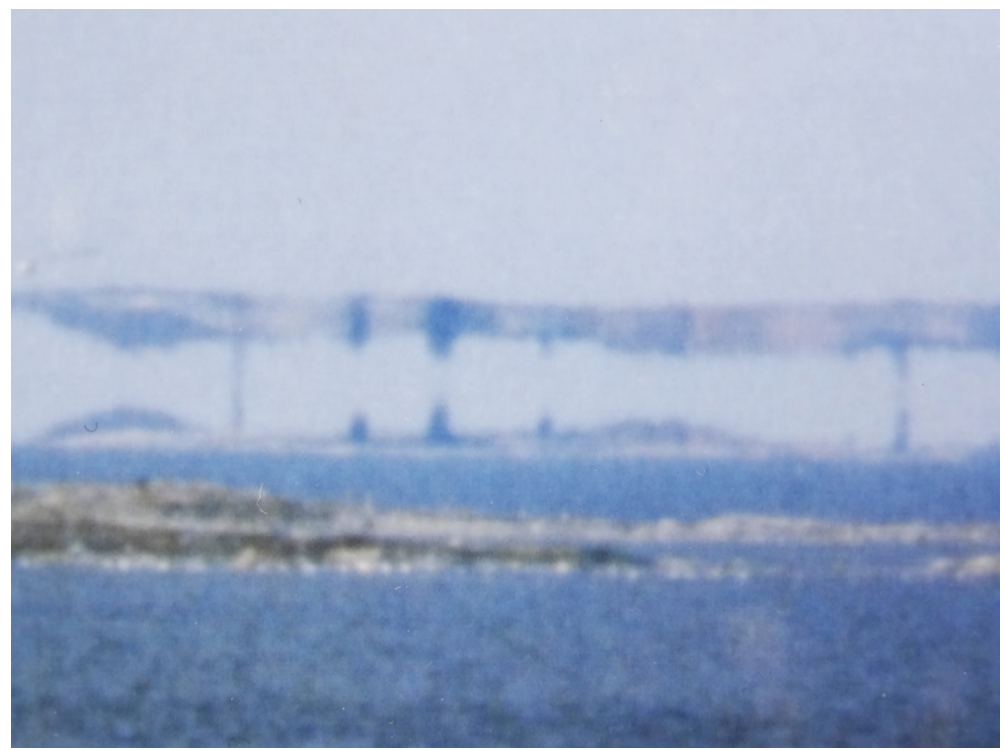

Figure 1. Superior mirage of islands and sea, seen over a cool surface (from Uusikaupunk, Finland). To be recognized are neck-like pillars (San giraffe?) and a horizontal stripe of (inverted) mirage horizon (San earsnake) (Courtesy of A. Takeno) (The somewhat blurred quality of a mirage picture is an inherent property due to atmospheric turbulence with its flickering light seen at large distances). 
The shaman had to travel spiritually to an inverted world and to prepare himself not only physically, but also mentally for that endeavor. He had to explore what it means to be and exist in an upside down world. Not all shamans may have seen with their own eyes an inverted and clearly visible mirage image of a landscape in the sky. But they may have, via oral tradition from earlier shamans, been given a clear concept of what it means to deal with an inverted world. This meant also to invert the body there and to assume an upside-down position (which leads to a trance like state, see below). It also meant to consider additional conditions which an inverted world may be imposing.

This is here assumed to be a "scientific" origin of shamanistic trance experience and trance journey. Trance experience resulted as side product of nature observation and of logic conclusions. Shamans saw an inverted world and found out experimentally what inversion of the body means. They experienced thereby trance sensations and accepted trance as a vehicle towards the inverted world. Palaeolithic shamans reacted, like they had always to do, when dealing with a harsh and hostile environment and a threatening destiny. They reacted logical and started to learn and to make experiments to explore the effects of an inverted world, which they wanted to contact, not only for rain, but also for many other human needs.

Such a naturalistic approach of understanding trance voyages, if supported by additional evidence, brings significant advantages: one can follow the ancient shaman's efforts again scientifically, because one understands what he saw as the inverted otherworld and what he intended to do. It will be shown below that first trance experiences of shaman may have indeed resulted from really assumed upside down positions experienced when exploring conditions of the inverted other world. Because of this credible link to the inverted other world trance experience may have become an important ritual and may have thus developed to a wide spread shamanic practice as understood today (Eliade, 1964; Lewis-Williams \& Dowson, 1989). And, if the approach turns out to be reasonable, extrapolations to shamanic rituals in palaeolithic caves, up to 40.000 years ago, as attempted below, may become more reliable.

Because of the barren land San people were living in, and their simple, original lifestyle, San rock art from Brandberg, Namibia, is used as an example and model to discuss and understand activities of shamans from hunter-gatherer tribes. Their acting and thinking may still be close to that in much earlier prehistoric communities. Special emphasis is thereby placed on tracing down evolution of shamanic trance experience as an attempt to adjust to an inverted world, which was occasionally seen in the sky and had to be visited for the benefit of the social group.

Superior mirages are natural phenomena experienced all over the world when there is a still over cool ground, closer to which the air becomes denser. There are places where they are seen quite frequently, but even the Alps in central Europe are one to two times a year seen partially inverted in the sky. The famous 
German geologist Alfred Wegener, who was first to propose the continental drift, wrote an article on this mirage phenomenon (Wegener, 1926; see also Reinke-Kunze, 2013), four photographs from December 31st, 2016 have, for example, been published by (Kaiser, 2016).

And such an occasionally seen inverted other world is actually part of mythological tradition in most cultures (see below). The trance journeys of shamans, as they were documented in many cultures, are consequently recognized and dealt with here as an early scientific project aimed at dealing with the other, inverted world.

\subsection{What Is Trance as a Vehicle for Shamanistic Experiences?}

From early written Greek records we know that the state of ecstasy or trance during religious ceremonies, accompanied by insensibility to pain, by hallucination, and non-susceptibility to ordinary sensation, was considered as an indication of union with God. An example was also the Dionysia/Bacchanalia, a cult related to the god Dionysos/Bacchus in the Greek-Roman world, organized to activate and welcome spring. This god was originally responsible for the powers of nature including animals and vegetation (before degrading to a god representing pleasure). The aim of his cult during the spring festival was to generate an "inverted" world by consuming psychedelic drugs, alcohol, toxic mushrooms and plants, by dressing as animals, using masks, talking nonsense and practicing intensive singing, shouting and dancing. These collective activities bear a strong resemblance to shamanism, where also seemingly non-rational behaviour is involved, where masks are applied, animals are invoked and where the aim is a change of consciousness and the perplexing situation of trance or ecstasy. The Bacchanalia celebrations became so popular and excessive, that in $186 \mathrm{BC}$ the Roman senate highly regulated them and even ordered many dedicated participants killed. Ecstatic forms of worship are also known from the early Christian church, but its origin in shamanism is, of course, much older. Ecstatic experience is typically associated with shamanistic performance and trance. Mircea Eliade even called shamans "technicians of ecstasy" (Eliade, 1964) (Many pictures and descriptions of shamanic rituals can be found on Internet when calling up the term "shamanic rituals" or consulting "shamanism" in Wikipedia).

For science it was not easy to understand this bizarre, intentionally invoked condition characterized by a not regularly working, awake brain. In earlier research on this phenomenon psychological illness such as schizophrenia was sometimes attributed to shaman personalities (compare Rock \& Krippner, 2011). Also magicians and charlatans were sometimes seen in them. But modern studies tend to value ecstasy or trance as shamanic strategies towards attending another spiritual state. They consider trance as an altered state of consciousness and investigate the possibility that trance acts as a vehicle supporting improved processing of information. They distinguish it from normal "waking" consciousness and search for clues towards hyper-functionality as the origin of the 
shamanistic voyaging concepts, applying sophisticated experimental tools of neuroscience such as EEG mapping and electromagnetic tomography (Flor-Henry et al., 2017).

Any state of awareness other than the normal waking consciousness may be defined as trance (definition presently adopted in Wikipedia for "trance"). In relation with shamanism trance experience is considered to be a vehicle to dissolve the boundary between the individual ego and a condition supposed to be associated with the other world. It seems not to be different from "deep hypnosis", and diverse techniques allow it to reach such a condition. Shamanism itself has been described to be a technique to reach a different state of perception, and not a religion or a cult itself (Stutley, 2003; Vitebsky, 1998). Shamans are believed to deliberately modify their conscious awareness to access otherwise "not available" information they intend to use in support of members of their social group. Eliade, after comparing Shamanism from all over the world argues that it must have had a common source in palaeolithic time (Eliade, 1964). Its age is confirmed by archaeologic evidence (VanPool, 2009). In the here presented study this ancient common source is seen and proposed to be rooted in the shaman's attempt to access the inverted world occasionally seen in a natural phenomenon, that of superior optical mirages (Figure 1), as explained further below. How the trance state itself later developed in social context is not the subject of this investigation.

Social, psychological, physiological and pharmacological techniques may induce trance. Physiological techniques include lack of sleep, exposure to extreme heat and cold, withdrawal of food and water, periodic sound of a drum or rhythmic dances with subsequent breath control. Ecstatic experiences, apparently, require a deprivation of sensory stimulation, trance experiences require sensory overstimulation. Both phenomena can be involved in shamanic experience and the consequence will be a condition of reduced and slowed down body functions. As dealt with later in more detail, one is essentially dealing with a reduction of the energy flux through the brain via a reduction of oxygen access, via physical, chemical or psychological stimuli.

Aldous Huxley already pointed out long ago that the experience in the brain is chemically conditioned. It appears to be oxygen deficiency, which causes trance experience as a result of hyperventilation or related stimuli. The cause of trance may be excitement, strong emotions, fear, panic, intoxication, pain, well directed breathing, monotonous stimuli. A normal situation for the human body is that for a comparably high carbon dioxide concentration in the blood the brain vessels are expanding to allow more oxygen to flow. During hyperventilation, too intensive breathing, the carbon dioxide concentration in the blood is however significantly reduced. This has the consequence that brain vessels are contracting. It has the paradox result that too much oxygen supply significantly reduces the supply of oxygen to the brain. Oxygen deficiency in the brain then generates trance experience by reducing awake consciousness and activating chemical 
stimuli. From San people in southern Africa it is known that they like dancing. During some of these dancing performances of a tribal group, which may involve ritual, the dances are resulting in trance. After hours of constant performing the dancers shorten their breathing and intentionally create oxygen deficiency. This leads to trance and finally can cause collapse. The path towards trance may thus involve many aspects.

In Tibet meditating Buddhist monks get engaged in long-winded singing with very deep voice, accompanied by drums. Oxygen deficiency in the brain must also here be a consequence. It is known that Tibetan Buddhism was inspired by Bön shamanism. The desire of contact to the other (inverted) spiritual world may have also been a relevant motivation in this case.

\section{Corner Pillars of Present Approach}

\subsection{What Is Consciousness and an Alternate State of Consciousness?}

A serious problem with research on the shamanistic voyage to a different state of consciousness is that consciousness itself, even though studied with sophisticated means, is presently not really understood. The author, however, proposed a qualitative explanation of what it should mean (Tributsch, 2016b; Tributsch, 2015) which here will act as a model to reflect about the mechanism of shamanic spiritual trance experience. According to this model of consciousness one is dealing with a self-organization of mere computation in the brain. This requires fast feedback processes between information modes, which necessitate a distinction between "before" and "after". A probabilistic, statistical time arrow (as favored today), involving many particles and many events towards increasing entropy cannot function here, where highly ordered systems are working. It must be energy turnover and generation of action, which is determining the beat of time. It can be shown that this "fundamental energy driven time arrow", derivable from the principle of least action (Tributsch, 2016a) is tolerating the statistical time arrow as a limiting case. Self-organization of information did consequently evolve, and functions like living matter, but on a spiritual basis, with neuronal architecture supporting it, and handling information in a higher hierarchy. This is proposed to be consciousness, a self-organized image formed to describe a person and his environment on the basis of available information (Figure 2).

When the activity of the brain is pushed sufficiently far from equilibrium by an adequate energy flow, and feedback processes are occurring between information modes, self-organization of computation will occur and gradually diversify depending on the energy through-flux, the distance from equilibrium, the information available, and the rate of information turnover (Figure 2). On the basis of signals from the body, from outside and from memory an image of our self is created, which allows us to judge our situation and to develop intentions. Like in biological evolution, simple forms of self-organization may precede more 


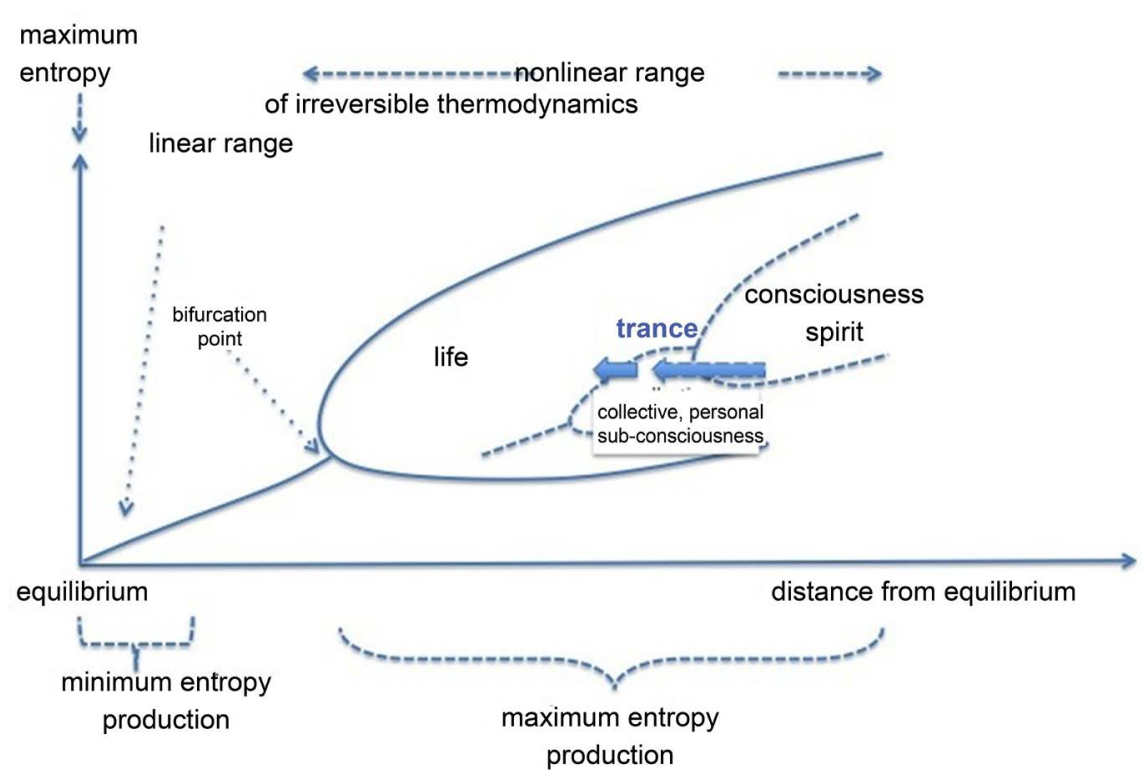

Figure 2. Within physical chemistry consciousness could be explained as a self-organization of information in the brain. This requires a large distance from equilibrium facilitated by a high flux of energy. During trance the conscious brain is deprived of oxygen (involved in energy turnover) and shifts closer to equilibrium. Thereby a simpler personal subconsciousness and a collective subconsciousness may be activated, which shamans may experience and access.

complicated forms. They may correspond to the collective and individual sub-consciousness (Figure 2). Quantitative EEG mapping and Low Resolution Electromagnetic Tomography in fact showed that during trance brain activities shift from the left hemispherical (rational) to the evolutionarily older right hemispherical state of "altered consciousness" (Flor-Henry et al., 2017). A transfer to more original, earlier states of consciousness is expected to occur also on the basis of the model discussed in Figure 2. Today trance is defined as a temporary marked alteration in the state of consciousness with a loss of a sense for personal identity. It can result from culture- or religion-specific activities, various modes of sensory perception, psychedelic or pathological conditions.

When, through lack of oxygen in the brain, caused by external or internal factors, the energy supply is reduced, then consciousness will shift to simpler forms which are sustained with less energy turnover. Here some forms of trance experiences may function. When even less energy is available, self-organized computation and consciousness will entirely cease to work.

What is known about effects of reduced oxygen supply to the brain? Quite a lot of information is available from high altitude mountaineering. A first indication of altitude sickness, which is observed above 3000 to 4000 meters, is tiredness and a strange kind of euphoria or elation, combined with partially irrational behavior and a lack of responsiveness. This altitude "intoxication" or "ecstasy" may intensify with altitude, finally leading to a loss of consciousness and ultimately to coma. Trance may be related to this altitude elation and intoxication 
because it is a state of awareness different from waking awareness.

\subsection{The Upside down, Inverted Otherworld and What It Meant for Humans}

In nearly all cultures the otherworld is, traditionally, imagined to be inverted. It is well known that both, ancient Babylonians and Egyptians, believed the otherworld to be an exact upside down image of the earthly world in the sky. For Babylonia this is, for example, pictured on a clay disc, showing the real world with Euphrat and Tigris and the mirror imaged heavenly one, conserved in the British Museum (reproduced in Tributsch, 1983, Figure 112). In an Egyptian book of the dead a woman, Anhai, prays (Rossiter, 1984): "Don't let me, in the next world, walk on my head". From the $2^{\text {nd }}$ millennium BC graves carved into rock in form of boats are known from the Balearic Islands. They are inverted for the other world with the keel upside, so that the boat is in the right position there. In the language of the Netsilik Inuit the land of the dead means "where they are crowding with hanging heads". Shamans returning from their mythical flights to the other world not infrequently told of people there living upside down. This means they were convinced of that. For burial, warriors from the bronze age got their sword fastened to the right hip, so they could react fast also in the other inverted world (Holmberg, 1925). People from the Aranda tribe in central Australia, when talking of the other world explained that the branches of the Ilumba-trees there are not growing upwards, as they grow on earth, but growing downwards (Strehlow, 1907). Langobard worriers had to ride, sitting backwards on their horse, towards Odin's shrine for worship, using their backward stretched arms to tear off a sample from a (ceremonial) pelt (Vita barbate Episcopi Benev.) (Menghin, 1985). In other ceremonies of different cultures clothes had to be dressed the wrong way, animals had to be conducted from the stable backward, male dresses had to be exchanged for female ones, images had to be turned around. Acts of inversion are already mentioned in the Lex Salica from the $6^{\text {th }}$ century (Lex Salica, 6th century).

The understanding was that they protected from problems with divine matters. Ancient Hindu tradition describes the universe as an inverted Banyan/Ashwattha tree with its roots in the higher worlds and its branches (downward) in the lower worlds (The Upanishads: Katha Upanishad). The concept of an inverted other world appears also to apply for China. The character describing the highest heaven of Taoists, for example, means "inverted view". In order to demonstrate, that this strong belief even survived in Christian medieval Europe, attention is pointed to the apsis of the dome of Speier in Germany from the $11^{\text {th }}$ century. It shows the paradise. How the artist imagined an inverted world is seen in the depicted relief figures. The paws of a lion are pointing backward. A knight is sitting backwards on his horse. This reminds of the ancient Greek god Dionysos, who also was depicted, on a coin, riding backward on a mule. Social inversions are known from the Roman Bacchanalia and Saturnalia 
festivities. A case of a surviving "social" inversion is the "Perchtenlauf" from Austria (Natko, 2014). Many rituals and believes related to an inverted world have been compiled and discussed (Fugger, 2013), also in relation to inverted mirage sceneries in the sky (Figure 1) (Tributsch, 1996).

\section{Where Did the Image of an Inverted other World Come from?}

\section{The Mirage Phenomenon Visibly Suggested Another Inverted World}

Mirage phenomena have accompanied prehistoric humans from the beginning of their existence. Especially when migrating and searching for animal prey they were much more fixed on the horizon than humans today. Under certain weather conditions they saw there superior mirages, which are sometimes very impressive (Figure 1), and in ancient time may have been seen much more frequently due to an unpolluted atmosphere. These mirages are caused by air density and temperature gradients above heated or cool ground and cause curved deviations from a straight propagation of light. Our brain, however, takes straight light propagation for granted, when recording it via the eyes. One sees a picture from where light rays are monitored to arrive into the eye. The consequence is that distorted and displaced images of a landscape are seen above and, seemingly, below ground. Due to changing atmospheric conditions they may sometimes show a remarkable dynamics. One is dealing with the only natural phenomenon, which is visibly suggesting the existence of another world. A prominent view is that of an inverted superior image of a landscape seen over a cool ground (Figure 3). Occasionally quite detailed features are recognized, as a superior mirage of a ship and a sailing boat shows (Figure 4).

In desert mirages, when looking over a heated surface, the sky and features of the landscape are seen in inferior mirror images. The sky reflections superposed to the ground are then perceived as water (Figure 5). Many historical and modern

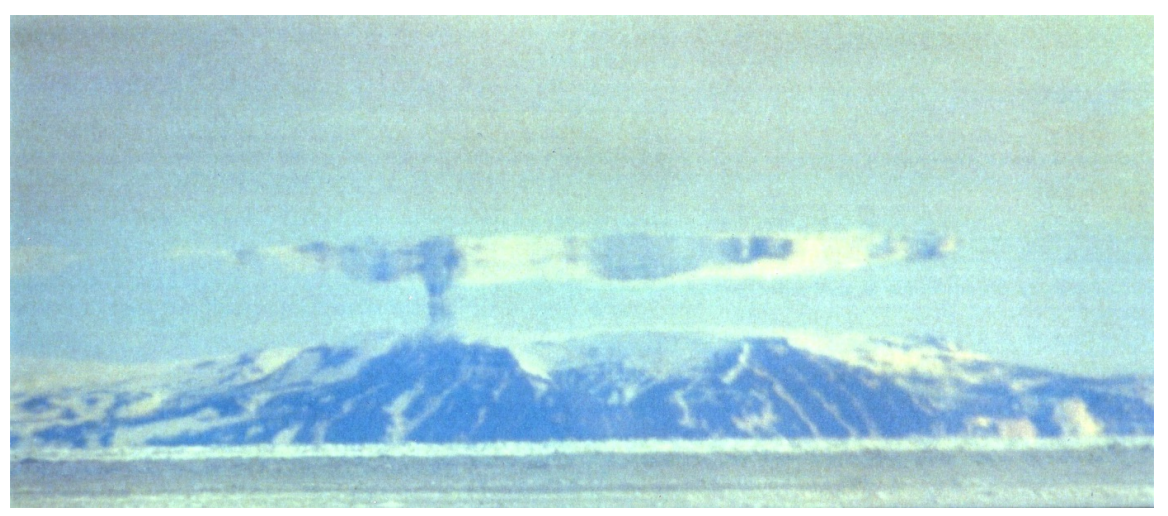

Figure 3. Superior mirage of a mountain range, generated by "curved" light paths (potographed at Resolute, Cornwallis Island, Canada) (Courtesy of A. Takeno). It shows an inverted landscape, occasionally seen over cool ground all over the world. It is assumed to be the prototype and model for the wide spread and deeply rooted traditional concept of an inverted other world. 


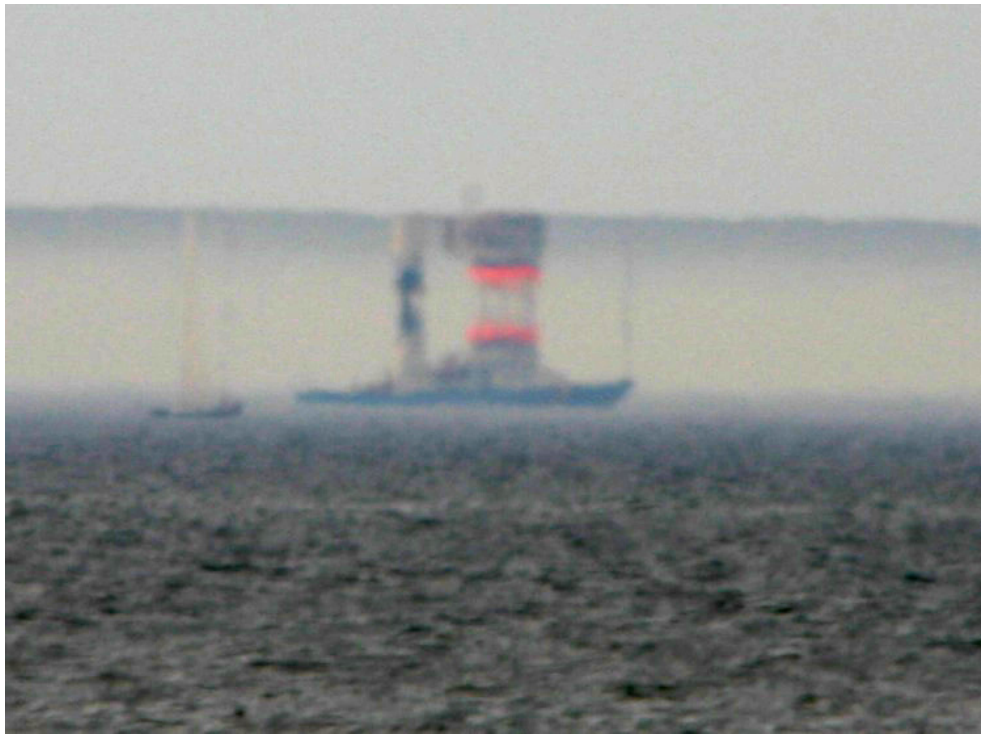

Figure 4. Superior mirage of a ship and a sailing boat, photographed at Binz, East Sea coast of Germany. It shows that objects appear vertically stretched (like a giraffe neck) and appear inverted, recognizable in greater detail. A snake-like horizontal stripe with inverted features appears (Photo: Tributsch).

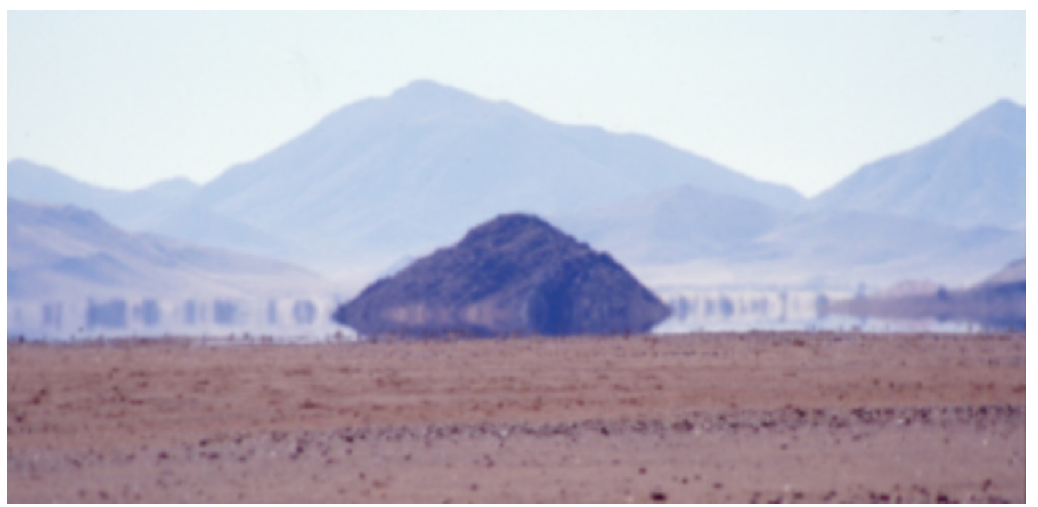

Figure 5. Inferior (desert) mirage (here photographed in an entirely dry Namib desert region), shows images from the sky superposed with the ground. Features appear imaged downwards and the sky color suggests water. Animals moving in such an environment would be seen doubled, stretched, suspended in air, or otherwise deformed (Photo: Tributsch).

reports of mirage encounters, as well as their modern explanation are discussed in (Tributsch, 1983). Reports of clearly visible inverted landscapes in the sky, and their mythological interpretations, are compiled in (Tributsch, 1996, chapter 4) (On the Internet impressive photographs can be seen when the terms "superior mirage" or "inferior mirage" are entered).

When animals are observed at a distance in a mirage, they are seen to be doubled, distorted, elongated or huge in size, suspended in air, and to behave very strangely, as if they would not be natural animals (seen now in some documentaries on desert life). A bird flying into a mirage doubles its wing pair. A gazelle may also be doubled or even walk in the sky, as if it would have wings. 
Desert animals may be seen to swim in water (which is actually a reflection of the sky). Since such animals were not acting that way normally, their behavior must in the far past have seen associated with the mirage phenomenon, the inverted other world, occasionally to be clearly recognized in the sky (Figure 1 and Figure 3). For early humans, migrating as hunters and gatherers, such phenomena must have been very present and the reason for frequent mental considerations.

Under favorable conditions, like in the Strait of Messina, Italy, fantastic superior mirages could sometimes be seen. It was still during the 17th century, in the year 1636, that the scientifically highly experienced Jesuit priest Athanasius Kircher was sent by the pope to this place to find out whether the observed phenomena were views form "heaven" or from "hell" (Kircher, 1671; Tributsch, 1983).

Only later, in the $18^{\text {th }}$ century, modern science began understanding the purely physical and feigned origin of mirage phenomena. Before, there was no reason to assume that these phenomena were not part of a really existing and meaningfully functioning nature. The always again seen inverted, but apparently functioning world in the sky, and the strangely mutated animals in its environment on the horizon, must have exerted a deep impression on prehistoric humans. When animals or persons are seen in an optical mirage they are not only seen inverted, or doubled, but sometimes also largely distorted. Very elongated figures are often recognized, but also animals that typically cannot fly, suspended in the air. Desert animals were also seen moving in (mirage) water. The inverted world was apparently associated with living beings of superior abilities (Tributsch, 1996).

\section{The Inverted World of Shamans}

\subsection{Symbols of Inversion in San Rock Art from Brandberg}

Only a small percentage of the approximately 50.000 rock figures from San (!Kung) on Brandberg mountain is related to shamanic ceremonies or mythological beings. Famous and much interpreted became the so-called "White Lady" from the Maak-cave (Breuil, 1955; Maak, 1966) (Figure 6(a)). In fact it is not a woman, but a disguised male shaman, shown in a ceremonial procession and with animals. He is shown in a procession with other persons, but with characteristically different appearance. He is partially painted with a white, not the darker brown real skin color, he wears long hair typical for women, his face is not recognizable and he shows a penis perforated with a thorn (more detailed drawings shown in (Lensen-Erz \& Erz, 2000). All these features can be interpreted as symbols of inversion. Even today in large areas of Africa ghosts from the other world are expected to be white (like the depicted San shaman). In San rock paintings from South Africa also a bending-forward: arms back posture of shamans is present as a form of inversion. This is not only a sign of inversion, because arms are usually not hold backwards. But this makes, when exerted in an 


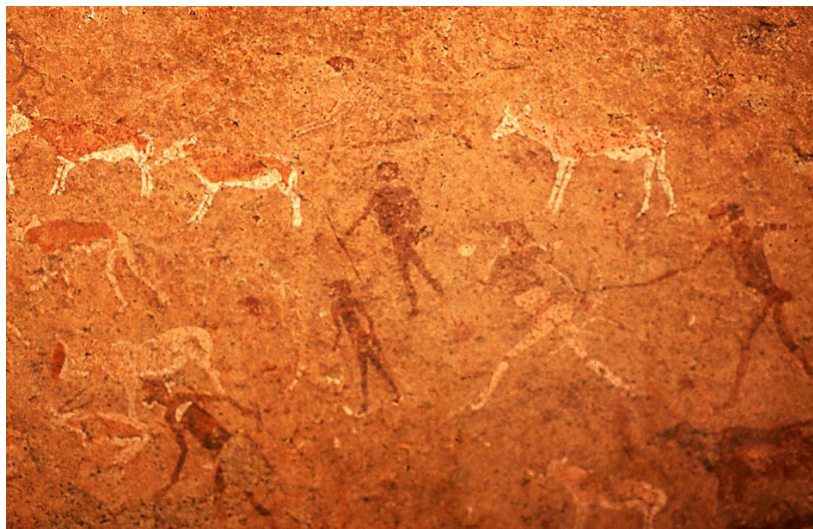

(a)

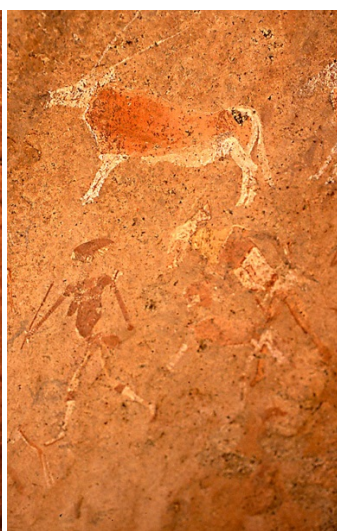

(b)

Figure 6. (a) Painting of the "White Lady" of Brandberg, which in fact is a man with inverted body features; (b) in the procession left from it there is, behind a woman, an additional shaman with a mask (Photos: Tributsch).

extreme way, also breathing difficult and may be a way of inducing oxygen deficiency and trance. With a perforated penis and the women hair style the shaman is not any more a man. He is a disguised shaman preparing for the voyage to the inverted other world. In the same cave of the "White Lady" there is another picture of a shaman depicted in a procession behind a woman (Figure 6(b)). He has also a perforated penis and is wearing a face mask. Where he goes he apparently does not want to be recognized.

A white painted body of a shaman fused with the front body of an antelope is shown in Figure 7.

Here a shaman is apparently travelling with his helping spirit, an antelope. His face is hidden also in this case.

Inversion in shamanic rituals is also well known from other parts of the world. Uralic and Altaic shamans apparently practiced full sexual inversion in the past. It includes elements of dresses or full costume from the opposite sex used during the rituals (Basilov, 1996). Sexual inversion and actions related to the other sex in relation to shamanism (discussed as Berdache phenomenon) has also been reported from many North American tribes specially from the Northern Plains groups such as Assinaboine, Crow, Cheyenne, Mandan, Omaha, Teton, Sioux, Cree, Blackfeet (Schaeffer, 1965; Klieger, 2017). This is remarkable, since red Indian men typically felt superior to women. In east-Nepal male shamans dress with long white women clothes and decorate themselves with voluptuous jewelry for their performance.

Shamanic sexual inversion has been linked to homosexuality and an origin from archaic matriarchy (discussed in: Stone, 2003). Here, the explanation is different. It is proposed that the shamans prepared themselves in their external appearance for the inverted other world, as they understood it, which also included sex inversion. In addition it was necessary not to be personally recognized. 


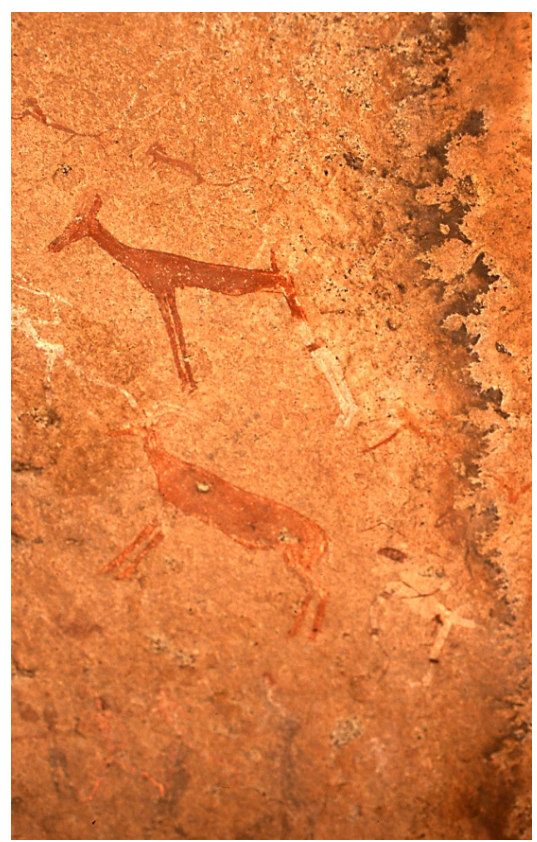

Figure 7. White painted human body with antelope top part from Maak cave on Brandberg (consider that the antelope front legs are much shorter than the human body). Below to the right there seems to be another shaman preparing for the voyage, with inverted body features (Photo: Tributsch).

\subsection{Mythical Rain Giraffe and Eared Rain Snake}

It has been pointed out that after the springbock, a highly appreciated prey, the rain giraffe (Figure 8) is the second most depicted animal in Brandberg San rock art (Maak, 1966). It is definitively related to the mythical symbol of the (non really existing) earsnake (Figure 9), since both, the giraffe and the earsnake are persistently depicted together (though only in $1 \%$ of the images (Lensen-Erz \& Erz, 2000). Above both, frequently rain in form of parallel lines is depicted (Figure 8, left). In addition the rainsnake is given the characteristic head of the giraffe with ears and sometimes the blunt horns. Furthermore rain-snakes with the typical net-shaped pattern of the giraffe are depicted (e.g. in Ga'aseb creek at Brandberg) (Lensen-Erz \& Erz, 2000).

The interpretation given is (Tributsch, 2000) that the giant rain bringing giraffes are the rising pillars on the horizon during formation of a mirage in the still before a rain storm (compare vertical features in Figure 1 and Figure 4). Later a snake-like mirrored portion of land parallel to the horizon appears and shows features of an inverted landscape (Figure 1 and Figure 4). One should also remember that the mirage patterns are seen moving in dependence of atmospheric conditions. The shamans took the "giraffe" and the "rain-snake" therefore for huge mythological beings. They were not beings seen in trance (as discussed in (Lewis-Williams \& Dowson, 1989), but really observed and interpreted phenomena. The inverted world of the latter, which can occasionally really be clearly seen (compare Figure 4), had to be accessed by the shaman during trance in order to finally control the rain (or to settle other matters). Since the 


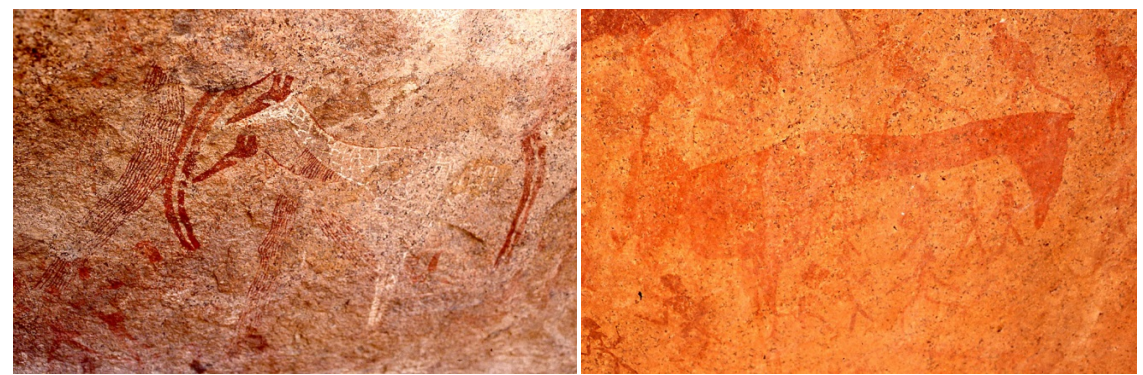

Figure 8. Huge mythological giraffes in San rock art at Brandberg are typically associated with rain, sometimes indicated by a pattern of parallel lines (left picture). Compare size relation between rain giraffe and persons (right picture) (Photos: Tributsch).

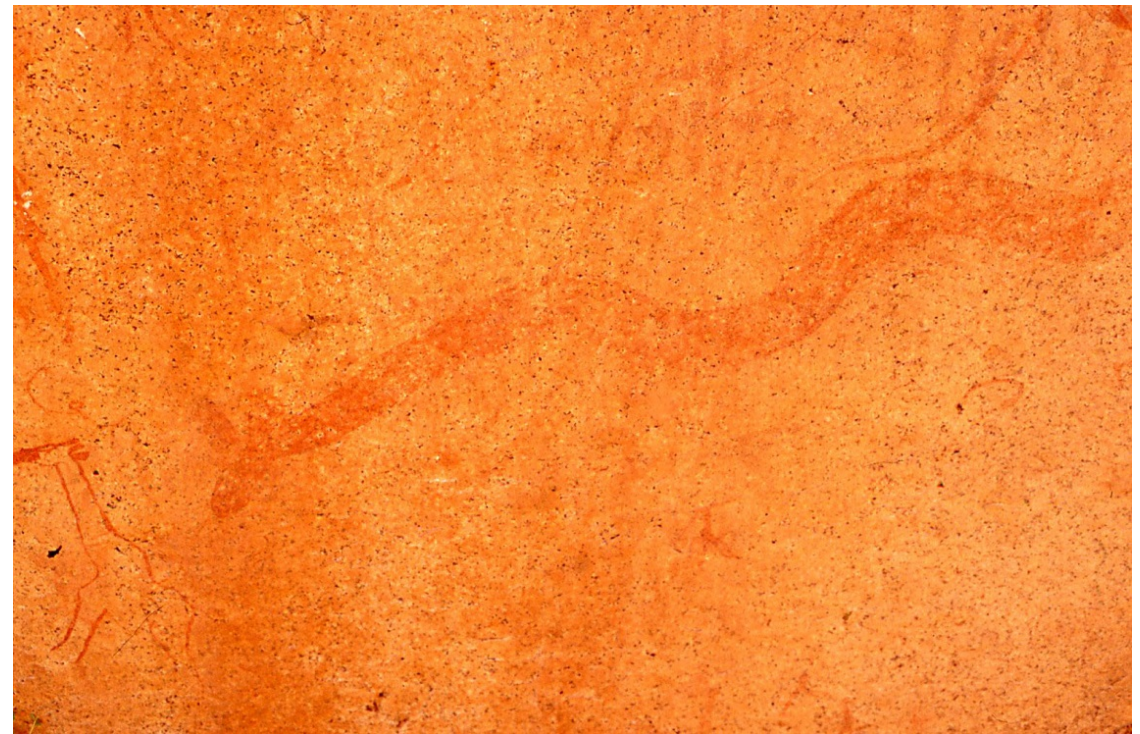

Figure 9. The rain bringing giraffe (here small in left bottom corner) and the huge (mythic) ear-snake shown together. The (giraffe) ears of the latter (and sometimes netlike (giraffe) patterns) show that they are related. In fact, in a superior mirage (Figure 1) the "snake" follows as mirage phenomenon (horizontal stripe) from neck-like pillars (giraffe?) on the horizon, often seen first (Photo: Tributsch).

eared rain snake typically appeared in the still before a storm, a success of the shaman's rain journey in trance was highly probable. Such a practical, functioning aspect of trance journeys may have strengthened the belief in rituals dealing with the inverted world and in trance itself.

\section{The Voyage of the Shaman to the Inverted Other World}

\subsection{Preparations for the Inverted World According to Brandberg Rock Art}

Early San shamans will have realized that the upper, rain bringing world was inverted. Their intention was to travel there in order to guide the desired rain to the preferred location. What would be the strategy to allow that? When the occasionally visible world in the sky was recognizable as inverted, maybe everything there was inverted. In order to access this inverted world (e.g. Figure 1 
and Figure 4) the shaman was prepared to invert his appearance. His skin color had to change and he camouflaged himself as woman. He also was hiding his face (for the reason see later). But he apparently also realized that his consciousness and perception must adapt to the inverted world as well. And this for a quite simple reason:

\subsection{Early Shamans Travelled in Upside down Position}

Early shamans may have tried to mimic the supposed (and occasionally actually seen) inverted otherworld (Figure 1, Figure 3 and Figure 4) by assuming an upside down position themselves. They imagined that only in such a position they could access the inverted world. What consequences does an upside down position have for humans and their health? There are a few medical statements, some reports on inverted bodies as consequence of accidents and many accounts of torture and execution by hanging people on their feet upside down. Of course, the resulting effects depend on the age of the person and on his health conditions (for a discussion of upside down position as a stunt see Stunt, 2017).

When a body is in upside down position blood rushes into the head, more blood flows towards the heart, which has to work harder. It fails to provide enough proficiency to keep the blood moving. The blood begins to pool and to expand capillaries in the brain. Blood clots start to form and begin to starve the organs from oxygen. Brain haemorrhage and heart problems may be consequences. Also vision may be affected. The biggest problem is however an increasing lack of oxygen in the blood and the brain, called asphyxiation. Epileptic attacks and coma may be the consequences. In the upside down position the organs in the abdomen put an extra weight on the lungs so that their working ability suffers. At the end every person hanging in the upside down position will die within one to two days. Already after 20 minutes consciousness may start to be significantly altered.

\subsection{Upside down Position as Symbol for Sorcery}

Shamans gave the impression of gaining extended and supernatural power from the trance ceremony. Here trance is related to early shaman's intention to assume an upside-down position. An important question is now whether one can find ancient information relating an upside down position to extraordinary spiritual abilities, such as supernatural power and magic. This would suggest, that shamans were actually attempting to imitate the upside down position for sorcery. First, Babylonian cylinder seals show beings from heaven in upside down position (redrawn in Tributsch, 1983, Figure 114). When fertility goddess Ishtar is depicted as scorpion, the scorpion appears in real and inverted position. The depiction of gods and semi-gods in upside down position already implies that they conserve their superior ability that way. In fact, they are superior because they are existing in upside down position. But what happens when they come down to earth? In the Koran (verse 2:102) a story is told about the two angels 
Harut and Marut that were sent to earth to lead humans into temptation. They however fell in love themselves with the beautiful woman Zuhra and tried to seduce her. This episode has inspired the Iranian poet and mystic Hafis from the $14^{\text {th }}$ century (Hafis, 1315-1390) who dedicated sensitive verses to this story (e.g. The Letter Elif, verse XV). While Zuhra was rewarded for her steadfastness and transferred into the morning star, the angels Harut and Marut received punishment. They were hanged on their feet upside down into a fountain near Babylon, where they should stay until the end of the world. A remarkable detail of this legend is, that people approaching these upside down hanging angels could talk with them, and could receive lessons in sorcery. Whoever wanted to learn magic was expected to refer to them. He was able to talk to them but did not see them in their inverted position in the fountain.

This ancient story of an episode with upside down positioned celestial beings, who master sorcery and magic (while in the Koran warning people to stay on the track of religious faith) testifies for the believe in a superior spiritual role of a world inverted for humans. A shaman, who aimed at mastering sorcery and magic had to approach the inverted world physically and spiritually. He had to face the upside down world to be able to act as sorcerer himself. This story provides the link between the inverted world, the upside down position and the shaman's strive for spiritual power and supernatural, magic abilities. The belief in superior wisdom rooted in an inverted world is also deducible from ancient Vedic wisdom (Bhagavad Gita, Chap. 15, Verse 1): “The blessed Lord said: There is a Banyan Tree with its roots upward and its branches down... One who knows this tree is the knower of the Vedas". According to Germanic mythology God Odin was hanging 9 days upside down in the tree Yggdrasil, which cleared his thoughts so that he invented the sacred writing in runes.

For people, however, the upside down position generates oxygen deficiency and trance. The shaman's logic reasoning consequently must have been that trance is essential for entering the realms of the inverted otherworld to gain spiritual power. This is proposed to explain the worldwide distribution of shamanic trance and ecstasy performances. They are not an arbitrary attribute, a simple invention of human spirit, as most trance researchers seem to believe. It is rather the consequence of a rational, straightforward plan aimed at reaching the inverted world to participate in its powerful mechanisms.

As shown before, the upside down position can be a confrontation with death for a human body. But Shamans have obviously explored ways out of such health risks. Maybe they experimented with hanging on arms in back posture, approaching the bending forward: arms back posture of San shamans, which makes breathing difficult (that San shamans were hanging in such a position is not deducible from San rock art, but without support from outside (e.g. gravitation) it is very difficult to maintain such a position for a reasonably long time). By probably patiently studying the effect of oxygen deficiency (which they certainly did not understand yet that way), they explored other strategies to gener- 
ate such an effect and the resulting trance. It is characterized by slowed down life functions and accompanied by shorter breath, slowed down heart beat frequency, lowered body temperature, lower sensitivity for pain and stiffer limbs. When consciousness is understood as a self-organization of information (Figure 2) this means that trance is moving the brain system more towards equilibrium, since less energy is turned over in the brain. This way more primitive and more partial forms of consciousness, personal and collective sub-consciousness may be activated, which requires less energy turnover. For a shaman this could still yield some valuable practical insight, as well as situations producing trans-rational images as suggested by some authors (Lewis-Williams \& Dowson, 1989). But more experience would be needed to understand this state, which resembles deep hypnosis, using advanced experimental techniques (Flor-Henry et al., 2017).

Anyway, the ancient knowledge of an occasionally visible inverted otherworld is claimed here to be the reason why shamans finally drifted into the trance experience as vehicle and access key to this inverted world. According to this line of thought, they did not just play with experiences and images, generated by an only partially or differently functioning brain during trance, as explained in (Lewis-Williams \& Dowson, 1989). It is proposed here that shamans were originally determined to follow a well defined purpose: they wanted to access the knowledge and power of the inverted otherworld. This way, and making experiments with the upside down position, they discovered trance as a vehicle towards gaining "supernatural power". Their trance journey thus became a scientific adventure based on logic thinking, like a well planned hunting expedition, an explorative search for ochre paint or the fabrication of stone tools. It is the same kind of everyday logic, which helped humans to survive in a natural environment.

\section{Discussion}

\subsection{The Trance Voyage of San Shamans}

Since immemorial times a shaman's aim in many traditional societies was to temporarily enter this other world, occasionally seen as an inverted image in the sky, for the benefit of his community. Attracting rain in periods of draught was one of San shaman's important tasks, discussed here. Other tasks included bewitching animals to facilitate their hunting, settling social conflicts, avoiding calamities, or to heal sick members of the tribe. In order to accomplish this, he had to deal with the inverted otherworld. For this he had not only to adjust his physical appearance but also his consciousness to an inverted existence. The trance state resulting from oxygen deficiency in the brain originally was experienced in the unhealthy upside down position of the body. It was gradually replaced by safer techniques for initiation of trance (and ecstasy). Shamans discovered that the situation of trance (oxygen deficiency in the brain) could also be reached via other, less dangerous practices. Shamans from the San people, for example, are dancing intensively for a long time, before they engage in short breathing as a 
doorway towards trance. According to the symbolic San depictions of inversion, found in rock paintings on Brandberg and explained above, a shaman had indeed to invert his physical appearance: his skin is not yellow-brown but white, as expected for ghosts in wide parts of Africa. He inverted his sex and had also to wear the long hair of females. He also bent his body strongly (or had his body bent that way) with arms stretched backwards, as shown in some South African rock paintings. This is also a sign of inversion and, additionally, hinders breathing. A shaman, having a face on earth, does not show it in the other world. Based on (assumed) very ancient experiments with upside down positions, shamans felt also compelled to travel in the state of trance, a state which may have subsequently been further refined and developed.

This trance state, recognized as a vehicle for accessing powers of the other world, is at present still little understood. But the interpretation of consciousness as an energy driven self-organization of information modes (Figure 2) allows understanding the effect of moderate oxygen deprivation. It may allow a gradual access to less organized and more primitive areas of personal and collective sub-consciousness (which seems also to follow from recent tomographic experiments (Flor-Henry et al., 2017). This may have contributed to the shaman's conviction that their journey is a really functioning spiritual experience with the prospect to contribute to the survival ability of human social groups.

Stone age hunter-gatherer societies like San tribal groups around Brandberg still lived during the last two centuries. Can we now better enter the inherited spiritual world of their shamans and also extrapolate to rituals of Palaeolithic shamans?

\subsection{Can We Now Better Understand Palaeolithic Shamanism?}

Palaeolithic and Neolithic paintings and artefacts in some 340 caves of France and Spain, in part dating back 40,000 years, have been thoroughly described and interpreted. The proposed explanations include: 1) rituals to increase animal populations; 2) hunting magic; 3) reproductions of trance experience of shamans; 4) initiation rituals for adolescent males; 5) rituals of females (Abbé Breuil, 1940) (cave art, 2017). Most discussed questions were also whether one is dealing with "art for art's sake" or whether it reflected a "magic ritual", what Abbé Henri Breuil, a pioneer in cave art research, believed.

On the basis of findings presented here, one can deduce an entirely rational, naturalistic new interpretation of Palaeolithic shamanism and cave painting: It is based on an ancient natural scientific theory dealing with the function of and communication with an inverted other world, as deduced from occasional sights as mirages of inverted land appearing in the sky (Figure 1 and Figure 3) or (seemingly) underground (Figure 4). The shamans tried to access the inverted other world via inversion in ceremonial and spiritual activity. But they may have also looked for help during their trance travel. They were aware of the strange, "unreal" beings around mirage phenomena and started claiming their support. 
They may have tried to use (unrealistically) flying, doubled, distorted animals and other phenomena seen in the flickering light of mirages as helping-spirits and magic spell to access the inverted world.

The cave, where the Palaeolithic ceremonies took place is already a place where inversion may occur (compare upside down mirror image of central hill, where ground is expected, in inferior mirage of Figure 4) and a counter pole to the sun illuminated earth surface. Palaeolithic shamans may have therefore assumed that underground caves are favorable locations for inversion ceremonies. The spitting of ochre- or carbon-liquid over a hand to form a hand-negative (hand stensil) can immediately be recognized as a sign of inversion (e.g. in Pech Merle cave (Figure 10), Chauvet cave). Not the hand, but the opposite, the missing hand is depicted in this quite abundant archaic symbol and this ceremony of inversion was apparently an important shamanic act (dating back 40.000 years, e.g. in cave of El Castillo in Spain or Pettakare cave on Sulavesi island, Indonesia). The shaman was calling up the inverted world using the stensil, the negative, of his (her) hand as, for example, also shown together with the 29,000 year old painting of the dotted horses in Pech Merle cave (Figure 10). Here one recognizes another indication pointing at the inverted mirage world: The dots, sprayed with the mouth, do not only cover the horses, but they are also all around the horses in the air. What else could better reproduce the flickering light typically seen in a mirage, than many dots, including those in the liquid sprayed with the mouth? The dotted horses are obviously depicted to be seen in a mirage. Why should this be the case? From within a mirage their image could more easily be moved into the inverted upper world, occasionally seen at the

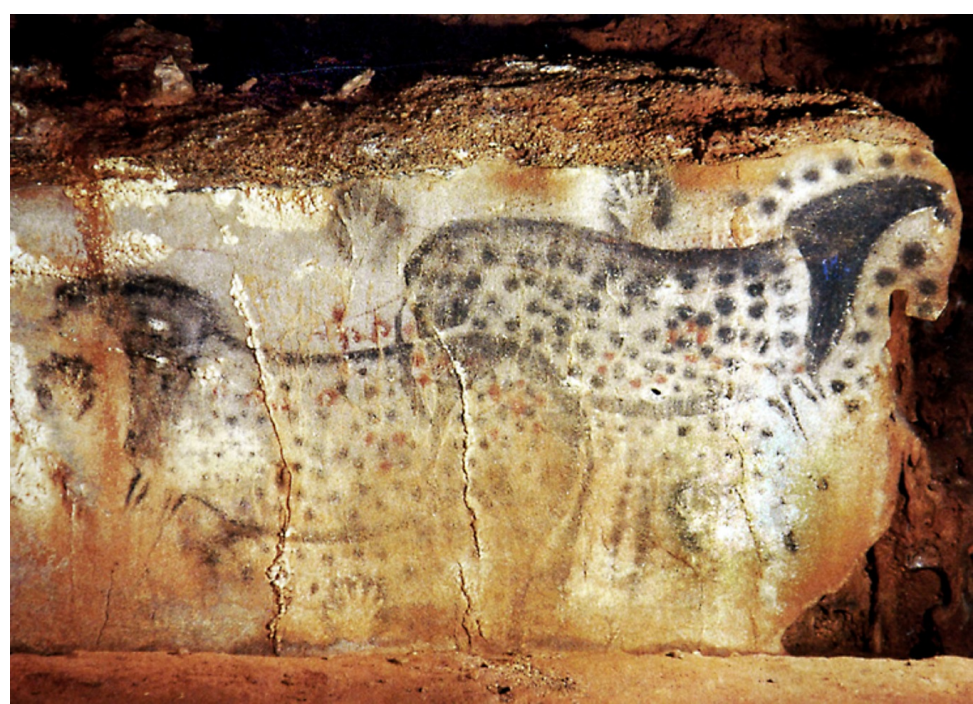

Figure 10. Inverted hands, hand stensils, are seen besides the 29,000 years old "spotted horses" of Pech Merle in France. The scene is shown in the flickering light of a mirage, expressed by spots on and around (!) the horses. Both, the hand stensils and the spots, are symbols of inversion, aimed at supporting the shaman's journey (with the upright horse image) to the inverted world for arranging the "waff" (http://www.bradshawfoundation.com/france/index.php). 
same apparent distance in the sky. There is, in the same cave, another group of flecks (or dots) together with a hand stensil (Figure 11). Such clouds of sprayed flecks or flecks printed with the palm are also encountered in the Chauvet cave (Sacred Heart Panel in Brunel Chamber, Entrance to Alcove of Yellow Horses). One animal, a bison or a rhino, is entirely produced by flecks or dots (hand palm prints) on the Panel of the Dotted Animal (Figure 11, right). The obvious interpretation here would be that the animal stands in the flickering light of a mirage, ready for being transferred into the inverted world, occasionally seen simultaneously (also impressionist painters one century ago used dots to express flickering light). The Red Dot Cluster in the Chauvet cave even suggests that the trance ceremony of inversion was planned to proceed in the flickering environment of a mirage (compare Figure 1).

It was apparently thought, that invoking this mirage property would facilitate the trance transport of the animal to the inverted otherworld. Until now these ancient dot-messages could not be rationally interpreted. Here the explanation fits.

Frequently, water (in fact reflected sky) is recognized in a mirage (e.g. Figure 5). Animals in a mirage are then seen swimming in this phantom water. Did Palaeolithic shamans use this mirage water to move animals close to the inverted world? In the Lascaux cave the frieze of "swimming stags" is well known. They may be swimming in mirage water. Are doubled animals, as frequently seen in a mirage, also shown in cave paintings? In the 30,000 years old Chauvet cave paintings the contours of some rhinos, are, strangely, drawn doubled (compare later). This is done in such a way that one does not have the impression of dealing with two independent animals. Maybe this double contour should

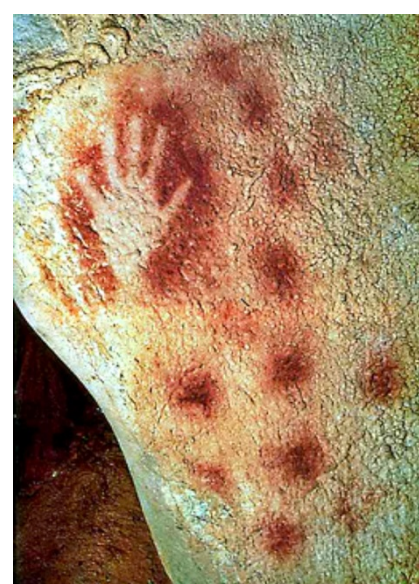

(a)

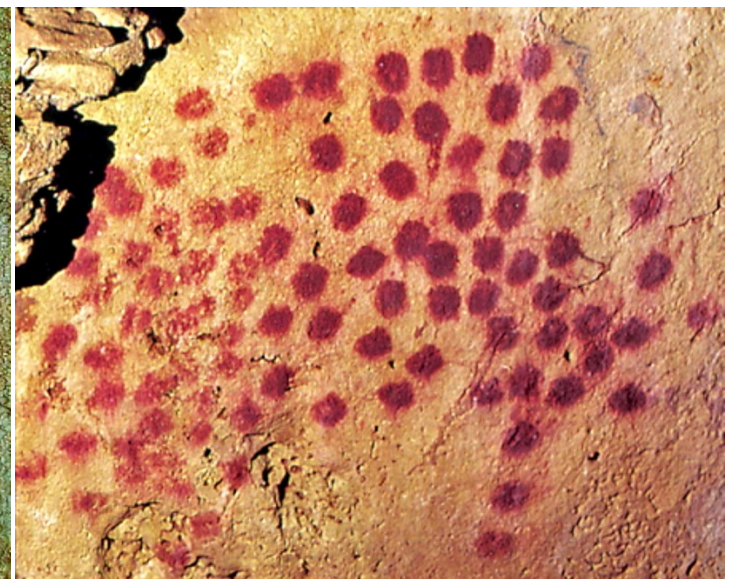

(b)

Figure 11. (a) Pech Merle cave: hand stensil and dots, interpreted as symbols of inversion in a flickering optical mirage. Retrieved from:

https://travelfranceonline.com/pech-merle-cave-negative-hands-quercy/; (b) Chauvet cave: Panel of the Dotted Animal. Retrieved from:

http://uk.phaidon.com/agenda/art/picture-galleries/2011/march/10/inside-the-cave-of-fo rgotten-dreams/ 
indicate that they are imagined doubled in a mirage. This shows that reasonable interpretations of Palaeolithic cave art are possible in context with the proposed naturalistic theory.

In the cave of Lascaux there is the well known sketched shaman with a birds head and hands as claws (see below). Besides, there is a standard with a bird symbol and a wounded or killed bison. Other prehistoric cave paintings with hominid figures with animal features are known from Les Tres Freres (human with deer top, like human with antelope top in San painting in Figure 7), Chauvet (half human, half bison), and other hominid figures in Altamira, Fontanet and Teyat. Why are shamans hiding their face and using animal helping spirits for guiding their voyage to the (inverted) other world? Also the face of a San shaman of Brandberg (Figure 6(b)) is hidden behind a mask and older figures show only symbolically sketched faces.

Meeting the inverted other world while showing the identity is too dangerous, apparently meaning death. It means death when an earthly image meets the inverted image from the other world. This is a superstitious traditional believe, which has survived until today. It is, for example, reflected in the superstition of the "waff" in Anglo Saxon (Northumberland) and north-Germanic folk tradition. The "waff" is an image of oneself from the other world. When one meets it or other people see it, this means death. One finds this believe also in older civilisations: In the Egyptian religious tradition every human had a mirror soul in the otherworld, the "Ka". Death comes when the "Ka" arrives to join the earthly soul. In the "Papyrus of Anhai" (1100 BC) it is depicted, how the two souls, shown as birds with women hands, join. The "Ka" soul is mirror imaged and has even its name written in mirrored hieroglyphs (Rossiter, 1984).

A shaman travelling to the inverted other world, of course, risked to meet his mirror image there. In order to escape from such a disaster he did not only have to invert his appearance and his consciousness, which gave him access to the inverted world. He also had to hide his personal identity. Otherwise, with his image appearing there, he faced death. Interestingly, the term "waff" has the same root as the north German word "wafeln". It relates to a horizon engaged in the reflections of a mirage. The relation of the "waff" to optical mirages, as interpreted here, is therefore obvious. The air around the dotted horses (Figure 10) "wafelt" (is waffing), and the shape of the "Dotted Animal" (Figure 11, right) is barely seen, because of the intensive flickering (waffing) of the air.

The concept of the "waff" must indeed have been derived from optical mirages and must be a very ancient spiritual concept explaining how the world works. How could it have developed? On the basis of understanding our world and the other world as mirror images it is quite reasonable to conclude, that when mirror images again join, when the earthly image joins the otherworld image again, life will terminate. This is, in fact, logic and rational, because one of the images disappears and only the heavenly one is expected to live on.

In superior mirages it can visibly be observes that earthly objects can "move" 
into the sky while inverting themselves. This may have become the role model for shamanic travel to the other (inverted) world. The natural phenomenon of a superior mirage may have suggested that such an enterprise is possible, but required inversion. It became something like an archaic, natural idol inviting idolatry in the sense of Mitchell (2008).

\subsection{The Animal Helping Spirits for the Voyage to the Inverted World}

Shamans preferred to travel with animal helping spirits. Where comes the idea of zoomorphic beings from, combinations of animals and humans or mythic animal figures with special power (e.g. Figure 7 and Figure 9)? This must originally also have been suggested by the optical mirages themselves. San people are famous for their ability of precise nature observation. Why is San rock art in southern Africa then showing mythic flying antelopes, double headed antelopes, besides of human figures with fish tails, very elongated human figures, humans with antelope heads (Tributsch, 1996) (Figure 12 and Figure 13). All these beings could perfectly be interpreted as really recognized appearances of animals and humans seen in and around optical mirages, close to where also the inverted world is occasionally seen. The animals and human beings seen together with and in relation to the inverted world are characteristically deformed and get additional, "mythical" properties, because they seem to behave very different from
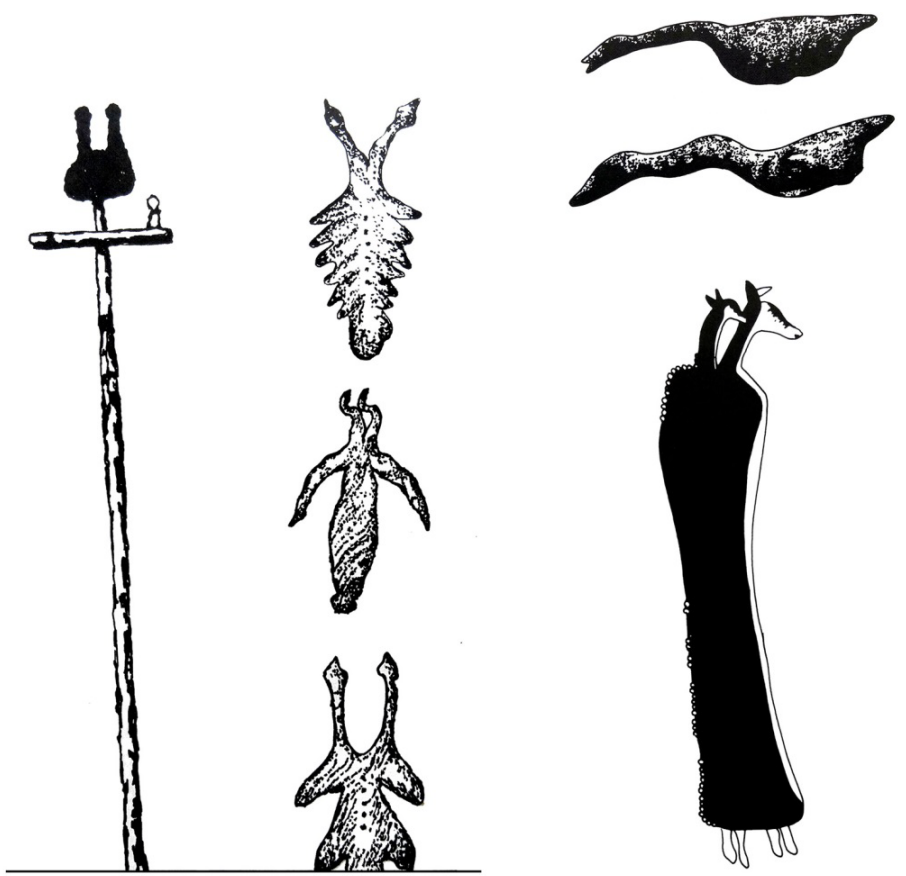

Figure 12. Siberian shamans (e.g. Ostiaks, Dolgans) preferred double birds as helping spirits for trance journeys (left side, MacCulloch, 1930). A shaman from the Canadian Dorset culture used a pair of ivory geese (top right). A double Eland antelope was the spiritual vehicle of a San shaman. Such doubled animals in full movement can be seen in a mirage (Tributsch, 1996). 


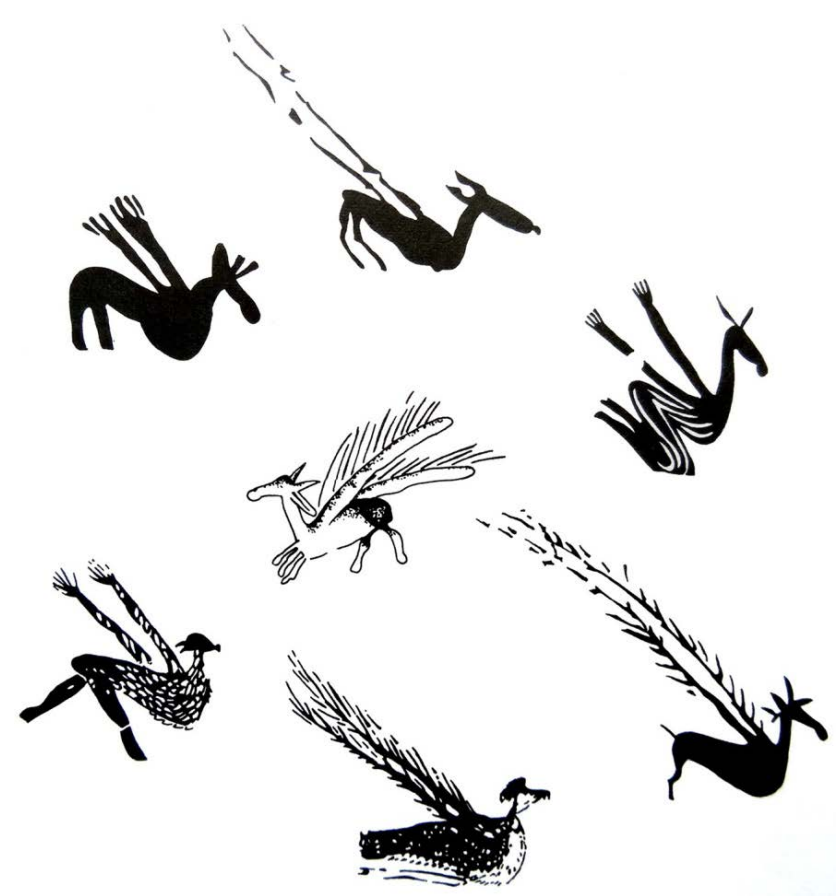

Figure 13. Flying antelopes are occasionally seen as in air suspended antelopes in a mirage together with the inverted world. Because of their assumed superior power they were adopted as helping spirits by San shamans and depicted in rock paintings in South Africa (Tributsch, 1996).

ordinary animals and humans. A bird seen flying into an optical mirage suddenly appears in doubled form. It continues flying but has now got four beating wings and two heads. Even today such an observation communicates a strange impression. What kind of bird is it? Double bird symbols, birds with two heads or four wings, actually were described as helping animals for Siberian and Canadian shamans (e.g. Yenisei-Ostiaks, Dolgans, Inuit, Dorset culture of Mansel Island (two gees)) (Figure 12, left).

They felt very comfortable travelling with such powerful companions, since they already seemed to be related to and belonging to the inverted world. Their exceptional abilities are excellent prerequisites for guiding shamans on their dangerous journey. Because of their high reputation double birds, for example, continued to serve also as messengers to the otherworld in numerous more recent mythological and religious traditions (Babylonian, Iranian, Celtic, Hittit, Byzantine, Germanic...) (discussed in Tributsch, 1996). Let us just mention the two swans linked by a golden chain, converting into a fairy, which picks up the fallen warrior in Celtic mythology, or the messenger raven pair of god Odin in Germanic religion.

Doubled, distorted and in air suspended, flying images of animals seen in mirages could have inspired shamans to claim animal helping spirits with exactly such properties for the spiritual voyage to the other world seen above in the sky. They appeared to belong to both worlds. And it is not surprising that also gods later used them for the trip down to earth. The Germanic God Odin did not only 
use a bird-pair as messengers, he also rode a (doubled) horse with eight legs. Also Ahora Mazda, the Iranian God venerated by Zoroaster, rode a two-headed horse on a coin from Taxila, where also a double-headed bird symbol decorated a pagoda from the $1^{\text {st }}$ century $\mathrm{AD}$.

When such "powerful animal spirits" are occasionally seen in relation with the inverted world on the horizon and in the sky, then they could be helpful in supporting the trance journey to this inverted otherworld. The shaman in the Lascaux cave has a bird's head (and a bird standard). A 35,000 year old figurine from the Schwäbische Alp in Germany shows a human with a lion head. When shamans are shown with animal heads (like in the San rock painting of Figure 7), then one is apparently faced with shamans who employ animal helping spirits and camouflage strategies during their trance journey. It can, of course, not be expected that later shamans, already living in settled social groups, still always knew details of animal forms seen in mirages. Their animal helping spirits then lost their mirage character (in contrast to helping spirits shown in Figure 12 and Figure 13). They became often ordinary animals, which themselves already are known to have superb abilities.

\subsection{Why Did Shamans Conjure with Corpulent Venuses?}

Shamans were not only responsible for successful hunting, but also for health and especially for critical situations like births. The famous, corpulent Venus of Willendorf (Austria) (Figure 14, left), 24,000 years old, has been interpreted as a symbol of fertility. No face is seen, but a head with ornamental patterns. An even more corpulent, rather grotesquely obese female figurine, carved from mammoth ivory, and dating 35,000 - 40,000 years back (basal Aurignacian), has been found 2008 in the HohleFels cave of the Schwäbische Alb in Germany (Figure 14, right). It has a minute head and a face is not at all visible (Conard, 2009). What role did such idols play and how could women, that lived in a steadily moving hunter-gatherer society under precarious condition have been so extremely corpulent, even obese?

On the basis of above considerations on shamans dealing with the inverted other world the assessment is straightforward: Because the faces of these corpulent women remain hidden the figures could be symbols or tools of inversion for (women?) shamans dealing with the inverted other world, probably during birth events. But when the faces are hidden for protection, camouflaged for the inverted world, then the corpulent bodies should also be bodies shown inverted for the other world. How did a shaman imagine a woman in the other inverted world? The idols were carved to be so opulent and well fed because they should show the opposite of what was true for the real world. In the inverted otherworld there was abundant food and pregnant women had enough to eat, have acquired abundant reserves. Then women bodies in the real stone age world, even when expecting a baby, were not corpulent but rather slim and emaciated. Women had a hard life and birth was a high risk for women in Palaeolithic hunter-gatherer 


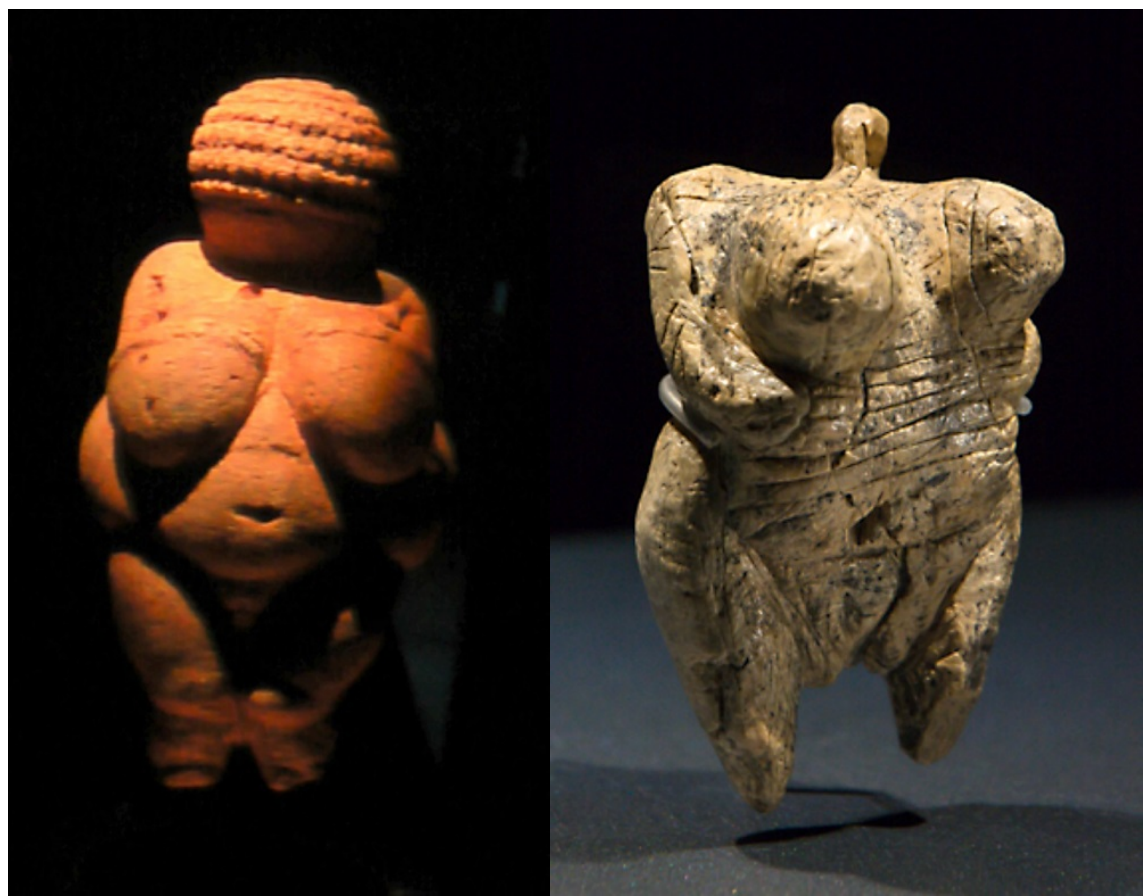

Figure 14. The Venus of Willendorf (left) and the Venus of HohleFels (right) are not symbols and depictions of earthly opulence. A shaman using it invoked the (desired) opposite condition, expected to prevail in the inverted other world, for emaciated stone age women expecting precarious birth (Foto: left: Tributsch, right: ThiloParg/Wikimedia, "license: CC BY-SA 3.0").

societies. From studies with tribes, which until recently lived such a lifestyle (e.g. Pygmies, San, Baka, Batek) it is known that women are generally small and thin. The reason is not only the migratory lifestyle and continuous movements, but also the predominantly vegetarian feeding as well as the custom to evenly distribute the (not frequent) animal prey among all tribal members.

The shamans apparently wanted, with these ritual symbols of opulent Venuses (Figure 14), to provide pregnant women with the much more favorable conditions expected for the other (inverted) world. But the face of the pregnant woman would not have been allowed there, because showing it in the other world would have meant the woman's death. She would have met her "waff". The corpulent, faceless female idols (Figure 14) should therefore, paradoxically, be seen as an indication for women's life of privation and risk in prehistoric times.

\subsection{Animal Cave Paintings as Tools for Invoking the "Waff"}

Why must the faces of these Venuses, when joining the shaman's journey to the inverted world, not be shown, but hidden? We now know the answer. Meeting the "waff", the mirror image in the other world, must be avoided. What, however, when a shaman intends to provoke the encounter with a "waff", when he wants to call up the death of a large prey animal for an imminent hunting expedition? Then, of course, he must, on his trance journey, take the animal's exact 
image to the inverted other world. It is not intended to be integrated into the inverted world via inversion, but only to face its "waff".

This consideration gives an idea of how the shamanic rite in the painted prehistoric caves may have proceeded 40,000 to 10,000 years ago. The shamans (and their supporters) went into the caves, which themselves already had features of the inverted world (because inverted landscapes are occasionally seen underground, Figure 4), and activated it additionally by well directed acts of inversion. They included the ceremony of spraying the negative of hands onto the walls, of calling up a situation of flickering light and image doubling, the camouflaging of the physical body by inverting its features (like in the above explained San rituals), and the ceremony to invert their personality by activating the trance state. When the shamans thus became "inverted" themselves, and had generated the inversion environment, the painted image of a selected animal from the steppes or forests was required for symbolic transport to the inverted world. The purpose was to induce what happens when such an animal from the earth surface meets its mirror image from the inverted world, the "waff". Projecting such a prospective prey animal into the conjured up other world means its approaching death. This way the animal was bound to die, was ready to be killed. Of course, the painting had to be so truthful and characteristic, even in different colors, that the animal could unmistakably be recognized. This explains why, in some prehistoric caves, even rock forms were used to make animals look more real, and sometimes three dimensional, partly engraved animal images were found, which were perfectly adapted to existing rock forms. Even characteristic dynamic movements of animals were occasionally shown in cave paintings. According to the then existing belief the planned hunting of such a spiritually marked and precisely depicted animal apparently became much more promising. This was considered an important advantage since hunting adventures were then quite dangerous because large, wild animals had to be approached at a close range.

This interpretation explains, why mostly big and difficult to access prey was depicted on the walls of prehistoric caves (mammoth, horse, bear, bison, musk ox, aurochs, deer, lion, ibex) and why sometimes spears are shown together with them. It also explains why an animal had to be painted quite naturally and characteristically. It had to perfectly match its "waff" in the other world to invoke its death. And, of course, it gives the simple reason, why often similar animal figures where repeatedly painted, or in other cases many different animals were painted one over the other (e.g. 76 mammoths in Chauvet cave, 158 mammoths in Rouffignac cave, many different superposed animals in Chauvet cave (End Chamber) (Figure 15). Hunting a big animal was not a single event but was repeated frequently over generations of hunters. This kind of depicted prey was, as some excavations (e.g. in Lascaux) show, not the principal source of food for prehistoric people, however was highly welcome because it promised a full stomach and unforgettable adventure. It is tempting to speculate what ceremony 


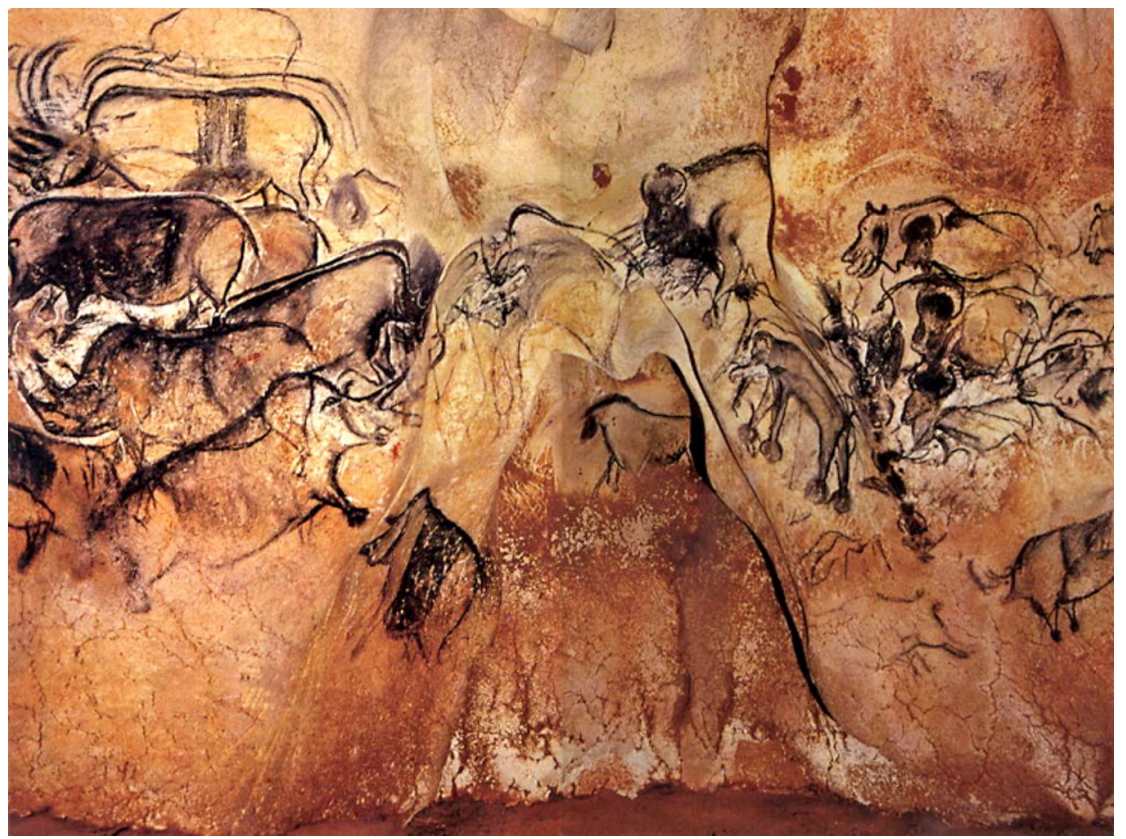

Figure 15. This detail of superposed animal paintings from the Chauvet End Cave in France convinces, that animals were not depicted for artistic beauty, but they were drawn for repetitious rituals, for which perfectly recognizable illustrations of specific animals were needed (https://misfitsandheroes.wordpress.com/2015/03/29/chauvet-cave/).

Palaeolithic hunters performed after finally killing an animal on which the spell of the inverted image, the "waff" had been cast. There must have been a ceremony of inversion! Maybe they did the same what hunters in Austria still do now: they congratulate the successful marksman indeed with a symbol of inversion. They congratulate him with the left (!), not the right hand. It may be a memory of a meaningful ancient hunting ritual.

One should remember, that the ceremonial picturing of an animal's "waff" only meant that the death of the animal became imminent. This was apparently considered a good precondition for a planned hunt of this animal. But hunters needed not to be the reason for the animal's subsequent death. If a group of lions threatened a camp, its shaman could have applied the "waff" spell for lions just in an attempt to get rid of the predators, not caring about the cause of their future death. In the Chauvet cave 72 painted animals are lions. Some lions are even characterized as a group, belonging together.

This interpretation of shamanic cave ceremonies also perfectly explains, why no trees, landscapes or mountains are reproduced on rock walls. There was no reason to apply a spell on them.

What logical procedure could have been followed by Palaeolithic shamans in relation to animal paintings, when performing their cave ritual? The aim, of course, was to get the real and the inverted mirror animal together in an effort to generate the "waff" for the deadly encounter. Shamans or their artists could have created, as just explained, the real upright image of an animal on the cave wall in order to transfer it to the other world via an inversion ceremony. Or they could 
have "travelled" to the other world via inversion, depicted the (sequestered) inverted animal there, and come back with it into the real world, where it appeared as the "waff".

Nearly all Palaeolithic cave pictures of animals show them upright. This indicates that the first strategy was applied. Only two presently known animal figures in Palaeolithic caves are painted upside down. It is the upside down horse in the Axial gallery of Lascaux, and the upside down bear in the Chauvet cave. In this case the "waff" from the inverted other world was conjured to hunt its mirror image in the real world. Above, in this study, San rock paintings were analyzed in an attempt to better understand the inversion procedures also of shamans of Palaeolithic sites. The expectation was that similar ideas could hold for hunter-gatherer tribes with similar lifestyle. Now, it can in inverse direction also be concluded, that San shamans supported hunting activities by accompanying painted prey animals (Eland antelopes, Springbocks) to the inverted world (Figure 6 and Figure 7), like shamans did in Palaeolithic caves (Figure 10 and Figure 15). Most animals on rock surfaces in southern Africa were also painted in upright position, but inverted, upside down antelopes are also known among San rock paintings (e.g. Dihlabeng District, Bethlehem and Kwa Zulu-Natal Drakensberg).

\subsection{Shaman and Bison from the Lascaux Cave}

The famous 15.000 to 17.000 years old cave painting of a shaman with a bison from the Lascaux cave (Figure 16, left) is still a subject of controversial discussions. After what has been said before a new analysis is possible and relatively straight forward.

1) The bison is painted in high quality and very characteristic, the shaman is just sketched, camouflaged as a bird-man. This means, that the bison is intended to meet his "waff" in the inverted world, to die. The shaman is masked and uses
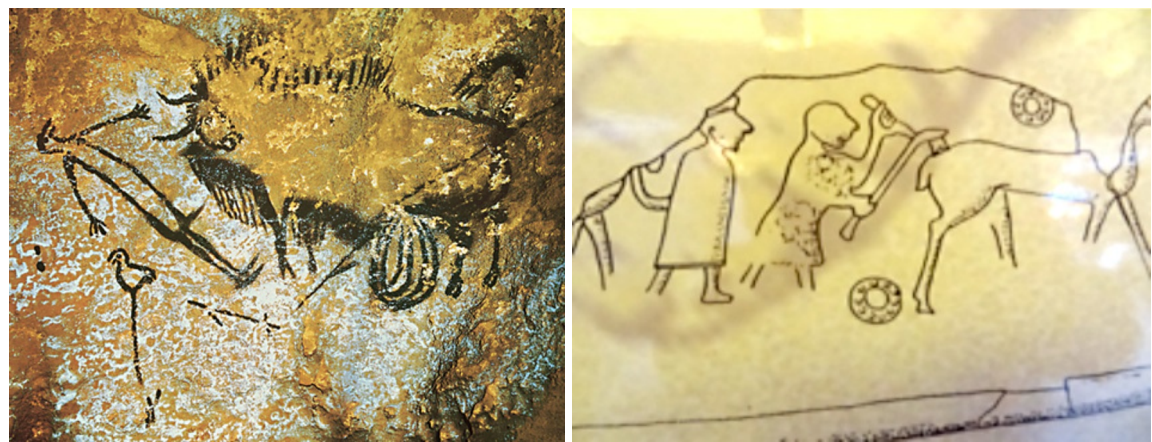

Figure 16. The famous bison-shaman picture from Lascaux cave

(http://www.lascaux.culture.fr/). It shows the killing of an animal from the wrong back side (left). Such "inverted" killings for the other world were still performed in sacrificial ceremonies during Celtic times (Eppan, Alto Adige, Italy, Foto: Tributsch) (right). The shaman's task on his staged trance journey was to take this bison to his mirror image in the inverted otherworld to provoke the killing of the real bison with a spear in the front side in the real world. 
a bird as helping spirit. He just accompanies the bison image and thereby visits the inverted otherworld in trance.

2) The spear visibly entered the bison from the backside and left it on the belly: No hunter would be proud of such an unprofessional killing. To get a spear through a bison's body that way and in such a steep angle is also entirely unrealistic. How can this be done with a wild bison and with such a penetration power? What one sees is apparently an "inverted" killing. The animal is not hit on the head and in the front part of the body, but it is hit on the backside. Also the fact that the spear is apparently shown broken may support that. Inverted killing is known to have been applied in animal sacrifices, intended for the otherworld (for example applied in Celtic tradition, Figure 16, right), and weapons in sacrifices for the other world were always broken. The inverted killing should mean that the "waff" of the bison in the otherworld should be hit that way. In turn, it was apparently expected, that the real bison on earth could then be hit by the real spear in the front of the body, as it should be.

3) The inversion aspects in relation to the shaman: The shaman is hiding his face, showing crawls as fingers, and he may have a "perforated", inactive (inverted) penis (apparently even visible) like trance travelling San shamans, showing sexual inversion. The trance situation could be reflected in the passive, lying position of the shaman. If he entered trance via the upside down position, or via an arms back position, he would have collapsed and would not any more stand upright.

4) The helping spirit strategy: The shaman obviously uses a bird as helping spirit. The "tail" of the bird on his standard looks strange and includes a dot. Maybe a double bird standard (as shown for Siberian shamans in Figure 12 left) is depicted in perspective. A double bird is a characteristic phenomenon of mirages. In addition the shaman is drawn very tall and slim. Compared to the European bison, which gets $3 \mathrm{~m}$ long and $1.9 \mathrm{~m}$ high, the shaman is $2.35 \mathrm{~m}$ tall (a man of that period would have measured 1.6 to $1.7 \mathrm{~m}$ ). He apparently assumes the sometimes very stretched form seen in a mirage (San paintings on rocks sometimes also shows very elongated figures, apparently of shamans (Tributsch, 1996). The shaman seemingly activated the stretching power of mirage phenomena for his trance journey to the inverted upper world. By the way: if the shaman-bison image would simply depict a hunting scene the artist would have exaggerated the size of the bison, and not the size of the shaman.

All together the idea of the Lascaux painting is to get support from the otherworld for a bison to be killed with a spear in the front. Without the spear (in the wrong, inverted side of the bison) the final nature of the bison's death would have been left open.

\subsection{The Ultimate Motivation for Animal Cave Art}

What changed in the evolution of humans, which finally induced them to paint impressive cave figures of animals and to create art work like the Venus figu- 
rines of Willendorf or from the Hohle Fels cave? It may be answered that by gradually evolving their brain and their survival ability humans became spiritually so alert as to ask themselves what occasionally seen inverted landscapes in the sky mean (Figure 1 and Figure 3). And because they were seen above in the sky and were not accessible they were expected to be sights of a superior world. Phenomena of superior optical mirages are the only natural phenomena, which visibly suggest another world in the sky. And this world was inverted. Like with many other natural phenomena prehistoric humans tried to learn how to deal with it. They did not understand its real nature (which even modern science only started to understand in the $18^{\text {th }}$ century). But mirages served to speculate that there is another world, which is interfering with the earthly one (what is actually seen in a mirage). This was the beginning of more complex mythological and religious believes, which were continuously matched and adapted considering occasional newer observations of mirages and new ideas (for a detailed study of mirage inspired ancient spiritual concepts and mythology see (Tributsch, 1996; Tributsch, 1983). Early shamans tried to learn how to access the inverted other world, in order to actively interfere in the hard reality of life. They may first have experimented by hanging upside down and have faced illness and death. Then they learned that the same trance state, induced by oxygen deficiency, and believed to be related to the other world (what ancient Greeks still assumed), could also be reached by alternative, safer techniques. One of these could have been the bending forward: arms back position, the San much later still applied.

Altogether, the shamanic efforts and experiences were early "scientific" strategies towards understanding and engaging a natural phenomenon, a superior mirage of an inverted world, for the benefit of the social group. The invoking of a trance state for dealing with the other world was a scientifically straightforward process (even though the theory, in the eyes of modern science, turns out to be wrong, because mirages project an illusion). This supports the suggestion by Bronislaw Malinowski, that science is as old as culture (Malinovski, 1944). The discovery, that early humans acted rationally and did not intentionally retreat into non-logic spiritual experiments, may help to much better explore and understand what prehistoric humans felt and how they acted. It will also be easier to follow evolution towards more sophisticated forms of religions since the concept of an inverted world survived in some of them until modern time.

But there is also another consequence, which deserves attention: if the proposed interpretation is correct, the art of painting and sculpturing in prehistory, the very first and explosive rise of art, did not start because of human's sudden attraction to aesthetics and beauty. This is already evidenced by the poorly accessible, dark and narrow cave environment. It started because it promised to be a tool for improved survival. It arose as part of a survival strategy. Art developed as utility art. The animals depicted in Palaeolithic caves became so characteristic and beautiful, even showing special perspective and motion, because they had to be recognized as images of existing, living animals in order to precisely act in the 
imagined deadly "waff" encounters. If the artists did not do a good job, this meant tragic consequences for the tribe in the eyes of then existing humans. Hunting success became, strangely, a criterion for the quality of the artist and the shaman involved (if they were not identical).

Also the Venuses were not carved in a strive for creating a symbol for beauty and femininity. They became so feminine and opulent, because they had to depict the inverse, the opposite of real life, which for Palaeolithic women was hard and full of privation. It was art probably intended to safeguard an imminent critical birth. The birth should proceed in the favorable environment of the inverted world.

All together it can be concluded that a natural phenomenon, atmospheric mirage patterns in the sky, stimulated intellectual, religious, mythological and artistic abilities in early humans, because it promised access to some control of destiny (in larger context discussed in Tributsch, 1996; Tributsch, 1983). The last shamans, still living today, should be met with the necessary respect. They are, according to the here presented approach, the remaining representatives of a now outdated and disproved "scientific" school, which, however, had very positive intentions and gradually developed a socially relevant, complex role. This ancient "scientific" school attempted what we may consider now to be magic ritual or alternate consciousness, but original efforts were based on rational thinking, and shamans apparently believed that the world works like that. For science, such a rational interpretation of the shamanic trance journey to an inverted other world, of the nature of animal helping spirits, and of the significance of animals in palaeolithic rock paintings affords the opportunity to learn more about the evolution of human spirit, evolution of religion and culture. The here given explanations of naturalistically inspired palaeolithic cave rituals and art make sense, because they seem to explain more than other thinking models and because they put pre-religious activities in line with other human efforts dealing with the natural environment and with survival.

\section{Outlook}

In contrast to a presently discussed view that prehistoric and more recent rock art and social ritual drew their character and dynamics from neuropsychological experiences and patterns generated during (arbitrarily or intentionally induced) shamanic trance experience (Lewis-Williams \& Dowson, 1993; Lewis-Williams \& Clottes, 1998; Lewis-Williams \& Challis, 2011, Lewis-Williams, 2004), the presented study attempted a natural scientific approach considering human exposure to and experience with the natural phenomenon of optical mirages. Trance experience and early art are not seen as initiatives, which were simply invented by the still unexplainable creativity of palaeolithic humans. They and their shamans were rather lured into trance experience, trance travel, cave art and ritual through challenging observations of natural landscape patterns mirrored into the sky. They were handled like other natural challenges and inter- 
preted as otherworld. Shamans wanted to access it attempting to invert their body themselves for gaining power. They thus bumped into the adventure of trance journeys and, stimulated by what they saw in mirages, selected animals with special properties, seen associated with mirages, as helping spirits for their ambitious undertaking. Much later Egyptians still believed in an inverted otherworld and used special animals (e.g. falcon, ibis, crocodile) for communication with their gods in a highly developed religion. Also medieval Christian religion still knew the inverted otherworld. Evangelists (mediators towards heaven) were associated with symbols of "winged", mythical animals (lion, bull), which normally cannot fly, and the throne of god is guarded by Cherubins, which show doubled and multiple wings and faces. This suggests that later religions have significant roots in ancient shamanic symbols, beliefs and rituals, which were shaped by optical mirage patterns, a natural phenomenon. What other significant observations shamans could have made during their long history of dealing with mirages as door to the other world? The most impressive superior mirage, occasionally seen in a rare situation of atmospheric inversion, is a triple image of the landscape: above the real one, an inverted one and again an upright one are seen. The earthly landscape thus temporarily splits up into three worlds and later returns to one world. This sometimes really discerned triple world may have become the model for the idol of trinity, which is deeply rooted in relevant religions worldwide, such as in Hinduism, in the expired Slavic, Celtic and Egyptian religion, or in Christianity (Tributsch, 1983, 1996). There was no need for the human brain to imagine and invent a three-fold other world or three deities in one, when nature itself suggested such an intricate concept to attentive observers.

\section{Conflicts of Interest}

The author declares no conflict of interest.

\section{References}

Basilov, V. N. (1996). Vestiges of Transvestism in Central Asian Shamanism. In V. Diószegi \& M Hoppál (Eds.), Shamanism in Siberia. Budapest.

Breuil, H. (1955). The White Lady of the Brandberg. London: Faber \& Faber.

Campbell, A. (2001). African Rock Art, Paintings and Engravings on Stone.

Chippindale, C., Smith, B., \& Tacon, P. S. (2000). Visions of Dynamic Power: Archaic Rock Painting, Altered States of Consciousness and "Clever Men" in Western Arnhem Land (NT), Australia. Cambridge Archaeological Journal, 10, 63-101. https://doi.org/10.1017/S0959774300000032

Conard, N. J. (2009). A Female Figurine from the Basal Aurignacian of Hohle Fels in Southwestern Germany. Nature, 459, 248.

Eliade, M. (1964). Shamanism: Archaic Technique of Ecstasy. New York: Bellingen Foundation.

Flor-Henry, P., Shapiro, Y., \& Sombrun, C. (2017). Brain Changes during a Shamanic Trance: Altered Modes of Consciousness, Hemispheric Laterality, and Systemic Psy- 
chobiology. Cogent Psychology, 4, Article ID: 1313522.

https://www.cogentoa.com/article/10.1080/23311908.2017.1313522.pdf

Fugger, D. (2013). Verkehrte Welten? Forschungen zum Motiv der riuellen Inversion, Walter de Gruyter.

Hamayon, R. (1990). La chasse à l'ame. Esquisse d'une théorie du shamanisme siberien. Nanterre: Sociétéd'ethnologie.

Harner, M. (1982). The Way of the Shaman. San Francisco: Harper Collins.

Holmberg, U. (1925). Vänster hand ochmotsols (Rig 8, pp. 23-36). Stockholm.

Jolly, P. (2002). Therianthrops in San Rock Art. South African Archaeological Bulletin, 57, 85-103. https://doi.org/10.2307/3888859

Kaiser, K. (2016)

http://home.eduhi.at/member/nature/met/atmoest/bilder2016/atm-erschein-oestbild.h $\underline{\mathrm{tm}}$

Kircher, A. (1671). Ars magnalucis et umbrae. (Cited in Brydone, Reisen durch Sizilien, Leipzig, 1774.)

Klieger, P. Ch. (2017). The Berdache as Shaman: An Analysis. http://soar.wichita.edu/bitstream/handle/10057/1786/LAJ_16.1_p35-45..pdf?sequence= $\underline{1}$

Le Quellec, J.-L. (2004). Rock Art in Africa: Mythology and Legend. Paris: Flammarion.

Le Quellec, J.-L. (2005). Rock Art Research in Southern Africa, 2000-2004, in Rock Art Studies. News of the World I, Oxford: Oxbow Books.

Lensen-Erz, T., \& Erz, M.-T. (2000). Brandberg. Der Bilderberg Namibias. Stuttgart: Jan Thorbecke Verlag.

Lewis-Williams, D. (1981). Believing and Seeing.

Lewis-Williams, D. J., \& Challis, S. (2011). Deciphering Ancient Minds: The Mystery of San Bushman Rock Art. London: Thames \& Hudson.

Lewis-Williams, D. J., \& Clottes, J. (1998). The Mind in the Cave: Altered Consciousness in the Upper Palaeolithic. Anthropology of Consciousness, 9, 13-21.

Lewis-Williams, D. J., \& Dowson, T. A. (1993). On Vision and Power in the Neolithic: Evidence from the Decorated Monuments. Current Anthropology, 34, 55-65.

Lewis-Williams, D., \& Dowson, T. A. (1989). Images of Power.

Lewis-Williams, J. D. (2004). Consciousness, Intelligence and Art: A View of the West European Upper Palaeolithic Transition. In G. Berghaus (Ed.), New Perspectives on Prehistoric Art: A View of the West European Middle to Upper Palaeolithic Transition (pp. 11-29). Westport: Praeger Publishers.

Lex Salica, Tit. 58, (6th Century). De chrencruda.

Maak, R. (1966). Die “Weisse Dame” vom Brandberg, Ethnologica N.F. (pp. 1-84).

MacCulloch, J. A. (1930). The Mythology of All Races.

Malinovski, B. A. (1944). Scientific Theory of Culture.

Menghin, W. (1985). Die Langobarden, Konrad Theiss Verlag, Stuttgart. Citation of Ancient Document: Vita Barbate Episcopi Benev.

Mitchell, W. J. T. (2008). Bildtheorie.

Natko, D. (2014). Ritual Rebellion and Social Inversion in Alpine Austria: Rethinking the "Perchtenlauf" in Its Relationship to the Carnivalesque. Tempe, AZ: Arizona State University.

https://search.proquest.com/openview/0da1b8dbfb5f08cla097247c840352d4/1?pq-orig 
$\underline{\text { site }=\text { gscholar } \& \mathrm{cbl}=18750 \& \text { diss }=\mathrm{y}}$

Pager, H. (1998). The Rock Paintings of the Upper Brandberg.

Peters, L. G. (1989). Shamanism: Phenomenology of a Spiritual Discipline. The Journal of Transpersonal Psychology, 21, 115.

Reinke-Kunze, Ch. (2013). Alfred Wegener: Polarforscher und Entdecker der Kontinentaldrift. Berlin: Springer.

Rock, A. J., \& Krippner, S. (2011). Demystifying Shamans and Their World: A Multidisciplinary Study.

Rossiter, E. (1984). The Book of the Dead: Papyri of Ani, Hunefer, Anhai. New York, NY: Liber.

Schaeffer, C. E. (1965). The Kutenai Female Berdache. Ethnohistory, 12, 190-216.

Stone, A. (2003). Explore Shamanism. Heart of Albion.

Strehlow, C. (1907). Mythen, Sagen und Märchen des Aranda Stammes in Zentral-Australien. Hermannsburg: Bearbeitet von M. Freiherr von Leonardi.

Stunt (2017). Upside down Stunt. http://abcnews.go.com/Health/story?id=5844197\&page $=1$

Stutley, M. (2003). Shamanism, An Introduction. Hove: Psychology Press.

Tributsch, H. (1983). Das Rätsel der Götter: Fata Margana. Frankfurt: Ullstein.

Tributsch, H. (1996). Als die Berge noch Flügel hatten: Die Fata Morgana in alten Kulturen, Mythen und Religionen. Frankfurt: Ullstein.

Tributsch, H. (2000). Does Mirage-Derived Mythology Give Access to San Rock Art? South African Archaeological Bulletin, 55, 71-76.

Tributsch, H. (2015). Irrationality in Nature or in Science? Probing a Rational Energy and Mind World. Scotts Valley, CA: Create Space.

Tributsch, H. (2016a). On the Fundamental Meaning of the Principle of Least Action and Consequences for a "Dynamic" Quantum Physics. Journal of Modern Physics, 7, 365-374. https://doi.org/10.4236/jmp.2016.74037

Tributsch, H. (2016b). A Fundamentally Irreversible World as an Opportunity towards a Consistent Understanding of Quantum and Cosmological Contexts. Journal of Modern Physics, 7, 1455-1482. http://www.scirp.org/journal/jmp

VanPool, C. S. (2009). The Signs of the Sacred: Identifying Shamans Using Archaeological Evidence. Journal of Anthropological Archaeology, 28, 177-190. https://doi.org/10.1016/j.jaa.2009.02.003

Vitebsky, P. (1998). Schamanismus. Reisen der Seele. Magische Kräfte. Ekstase und Heilung. München: Taschen Verlag.

Wegener, A. (1926). Die prognostische Bedeutung der Luftspiegelung nach oben (pp. 93-95). Ann.d. Hydrogr., Köpenheft.

Winkelman, M. (2010). The Shamanic Paradigm: Evidence from Ethnology, Neuropsychology and Ethology. Time and Mind, 3, 159-182. https://doi.org/10.2752/175169610X12632240392758

Wright, P. A. (1989). The Nature of the Shamanic State of Consciousness: A Review. Journal of Psychoactive Drugs, 21, 25-33.

https://doi.org/10.1080/02791072.1989.10472140 